\title{
Contribution to the modeling of hydration and chemical shrinkage of slag-blended cement at early age
}

\author{
Tarek Merzouki ${ }^{\mathrm{a}, 1}$, Marwen Bouasker ${ }^{\mathrm{b}, *}$, Nour El Houda Khalifa ${ }^{c}$, Pierre Mounanga ${ }^{\mathrm{d}}$ \\ a PRISME EA4229, University of Orléans, 8 rue Léonard de Vinci, 45072 Orléans, France \\ ${ }^{\mathrm{b}}$ University of Orleans, Research Center in Divided Matter-CRMD, FRE CNRS 3520, $1 \mathrm{~b}$ rue de la Frollerie, 45100 Orleans, France \\ ${ }^{\mathrm{c}}$ Laboratory Systems and Applied Mechanics - LASMAP, BP 743, La Marsa 2078, Tunisia

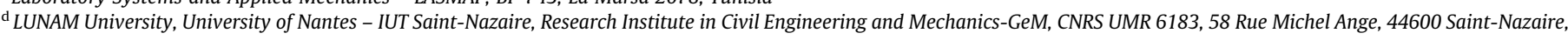 \\ France
}

This paper presents a contribution to the modeling of the chemical shrinkage of the slag-blended cement paste (binder) at early age. Assuming that the chemical shrinkage is a direct result of hydration, the hydration modeling of slag-blended cement was studied by considering the interaction between the hydrations of blast furnace slag (BFS) and ordinary Portland cement. The reaction of BFS in the presence of calcium hydroxide $\mathrm{CH}$ (Portlandite) produced from the hydration of the cement was investigated. The kinetic hydration of cement was developed, and the volume phases in the cementitious material during the hydration process were calculated. The chemical shrinkage, which is the negative volume balance between the reactants and the products formed, is then calculated. In parallel with this numerical modeling, an experimental study was conducted to investigate the effect of slag's addition $(0 \%, 30 \%, 50 \%$ and $80 \%$ ) on the heat of hydration and chemical shrinkage at early age (maturation up to 7 days). The proposed hydration model incorporates the effect of following variables; the chemical composition of the binder, the fineness, the water to binder ratio $(w / b)$, the curing time and the temperature.

\section{Introduction}

Recently, autogenous shrinkage is considered as one of the phenomena clearly identified as the origin of the (micro) cracking of cementitious materials used in the design of civil engineering structures. When, is prevented, the shrinkage is responsible for the formation of microcracks in the area surrounding the aggregates and through cracks in the binding matrix. This leads to an increase of the porosity and therefore loss containment characteristics of material and an increase in its permeability.

\footnotetext{
* Corresponding author. Tel.: +33 (0)2 384927 71; fax: +33 (0)2 38417063 . E-mail address: marwen.bouasker@univ-orleans.fr (M. Bouasker).

${ }^{1}$ Laboratory of Systems Engineering of Versailles (LISV), University of Versailles Saint-Quentin, 10-12 avenue de l'Europe, 78140 Vélisy, France.
}

The durability of buildings depends, among other dimensional changes on the cement matrix at very early-age.

The autogenous shrinkage is a physico-chemical phenomenon coupled to mechanical capillary effects due to consumption of pore water during the hydration. The origin of this deformation has been studied extensively in the literature [1-3]. This deformation is due to chemical shrinkage, (also called "Le Chatelier contraction") subsequent to the negative volume balance of hydration reactions. The chemical shrinkage gives a capillary effect which creates an internal tensile stresses within the cement matrix. At early-age, these stresses are often higher than the breaking stress of the material, hence the occurrence of (micro) cracks.

For Portland cement, the relationship between chemical shrinkage and the hydration degree is almost linear [4,5]. Indeed, the knowledge of hydration reactions in the case of cement matrices 
based on Portland cement was used to determine the chemical composition of the matrix versus time [6,7]. Knowledge of the fraction of each component and its density allows the easy determination of the chemical shrinkage.

Contrary to the clinker, slag needs activators such as sulfates and alkali to react with water [8]. During the hydration of Portland cement, $\mathrm{CH}$ and sulfate are produced. Therefore, a good combination of slag and Portland cement can form a binder with good reactivity and hence high performance. The modeling of the slag hydration in the blended cement is more complex than that of the clinker. The hydration of slag depends on several important parameters such as: the slag reactivity, the pore solution composition, the activators such as sulfates and Portlandite $(\mathrm{CH})$, temperature and the water to binder ratio. Or, some parameters are influenced by the cement hydration. So, hydration reactions of the slag-blended cements are mutually influenced. For example, the addition of slag can accelerate the hydration of $C_{3} S, C_{3} A$ and $\mathrm{C}_{4} \mathrm{AF}$ at different degrees [9].

The process of hydration of the slag with cement can be divided into two stages [10]. Firstly, the slag reacts with alkali metal hydroxides which are dissolved immediately when the Portland cement is mixed with water. Once the concentration of Portlandite $(\mathrm{CH})$ reaches a certain value, the reaction with $\mathrm{CH}$ becomes dominant. This reaction is responsible for the occurrence of an additional peak in the heat of hydration curves [11]. The slag content is a primary factor in the hydration of blended cements. However, the effect of slag content on the hydration process of cementitious is a current topic that deserves to be more explored. The cement and slag hydrate at different rates. After being mixed with water, cement in the binder starts to hydrate immediately. Meanwhile, a small amount of slag reacts, probably due to the presence of gypsum in cement [12]. Then, the hydration of slag is heavily activated by alkalis and later by the Portlandite $\mathrm{CH}$ produced by the hydration of the cement. Generally, the slag hydration rate is far lower than that of clinker [12]. After one year, about $90 \%-100 \%$ of the clinker has hydrated in the binder [9]. At the same age, only about $50 \%-70 \%$ of the slag has hydrated [13].

In literature, there are several models that simulate the hydration of cement which take into account the reaction of slag. The first models are very general and are often derived from experimental results [9,14-16]. Schindler and Folliard [15], proposed a general hydration model that could predict the heat evolution of cementitious materials. The proposed model takes into account the effects of various variables: such as cement chemical composition, cement fineness, supplementary cementing materials (fly ash, and ground-granulated blast-furnace) and mixture proportions. De Schutter $[17,18]$ proposed a general kinetic hydration model both for Portland cement and slag-blended cement based on the isothermal microcalorimetry experimental results. The model of De Schutter does not take into account the chemical composition of the cement and slag. Maekawa et al. [19,20] proposed a general hydration model for cementitious materials, incorporating fly ash and slag. The reactions of fly ash and slag are treated separately from those of ordinary Portland cement, and some interactions are taken into account through the free water content and the calcium hydroxide concentration. Based on the consideration of the exothermic characteristic and the reaction ratio of the slag, Tanaka et al. [21] proposed a method to estimate the adiabatic temperature rise in slag blended concrete. It should be noted that, most of general models do not explicitly consider the interactions between the cement hydration and the reaction of mineral admixtures, such as the production of Portlandite by cement hydration and its consumption by slag reaction.

Benefiting from the rapid development of knowledge in cement chemistry and computer science, several computer models have been developed by various groups. These models can simulate the chemical reactions going on during the hardening process of cement paste, and microstructure development taking into account the mineral admixtures such as blast furnace slag. These models fall into two categories: thermodynamic models and multiphasic models.

The thermodynamic modeling was done using geochemical computer code (GEMS) based on a Gibbs energy minimization algorithm [22-24]. Another thermodynamic model was developed by Pietersen and Bijen [25] to study the reactivity of fly ash and blast furnace slag in cement. These thermodynamic models show that the reactivity of blast furnace slag changes in volume at different phases over time. However, these models require a thermodynamic database large enough for all the chemical species that come into play. For example, an important database was developed ( $\mathrm{Na}-$ gra), for supplying the computer code GEMS.

The last type of modeling is the multiphasic Kinetic modeling. Bentz [26] attempted to simulate the reaction of slag with CEMHYD3D (NIST version). The model treats the hydration products of slag as a homogenous mix, namely "slag gel", whose properties are postulated from the slag composition and are independent on other factors. Chen [27] proposed a new theory able to predict the types of reaction products, their quantities and properties with considerations to the interactions between the reactions of slag and clinker in cement. Wang et al. [28] proposed a kinetic hydration model to simulate the hydration of concrete containing fly ash and slag. By considering the production of calcium hydroxide in cement hydration and its consumption during the reactions of the mineral admixtures, the reaction of fly ash and slag was separated from that of cement hydration. The heat evolution rate of blended concrete was determined by the contributions of both the cement hydration and the reactions of the mineral admixtures. The common objective of these studies is the simulation of hydration in the presence of slag at various proportions. The problem often encountered is the kinetic reaction of the slag. In fact, the stoichiometric coefficients of the reaction are still poorly understood.

Chen et al. [12] proposed three reaction models for slag blended cement. These models depend on the amount of calcium hydroxide entering the slag hydration; the first model: No $\mathrm{CH}$ enters the $\mathrm{C}-\mathrm{S}-\mathrm{H}$ formed by the slag hydration; the second model: $\mathrm{CH}$ enters $\mathrm{C}-\mathrm{S}-\mathrm{H}$ from the slag hydration to sustain a $\mathrm{C} / \mathrm{S}$ ratio 1.8 ; the third model, considers that, a part of $\mathrm{CH}$ enters $\mathrm{C}-\mathrm{S}-\mathrm{H}$ from the slag hydration. Among these three models, the author found that the third model gives the best predictions for the composition of the main hydration product, $\mathrm{C}-\mathrm{S}-\mathrm{H}$, especially for its $\mathrm{C} / \mathrm{S}$ ratio. In the model of Chen et al. [12], the $\mathrm{C} / \mathrm{S}$ and $\mathrm{A} / \mathrm{S}$ ratios are coupled by the relation proposed by Richardson [29], and on the basis of experimental tests made on a series of pastes of cement and slag. According to Taylor [30], the values of the ratios $\mathrm{C} / \mathrm{S}$ and $\mathrm{A} / \mathrm{C}$ in the $\mathrm{C}-\mathrm{S}-\mathrm{H}$ were assumed beforehand to be 1.55 and 0.045 , respectively.

Richardson [16] studied the stoichiometry of the reaction between the slag and Portlandite $(\mathrm{CH})$ as a function of temperature and the $\mathrm{CH} /$ slag ratio. The author found experimentally that each mole of slag consumes $2.6 \mathrm{~mol}$ of $\mathrm{CH}$. The $\mathrm{C} / \mathrm{S}$ andA/S ratios in $\mathrm{C}-\mathrm{S}-\mathrm{H}$ was determined preliminary to a values of 1.42 and 0.046 , respectively. Biernacki [31] and Richardson [16] show that the composition of $\mathrm{C}-\mathrm{S}-\mathrm{H}$ is clearly influenced by the slag proportions in the mixture. Increasing slag proportions resulted in decreasing $\mathrm{C} / \mathrm{S}$ ratios and increasing $\mathrm{A} / \mathrm{S}$ ratios in $\mathrm{C}-\mathrm{S}-\mathrm{H}$.

In the present work, a kinetic hydration model to simulate the hydration of cement pastes containing blast furnace slag is proposed. Considering the production of calcium hydroxide in cement hydration and its consumption by the slag hydration, the reaction of slag is treated separately from that of cement hydration. The reaction of slag was evaluated as a function of the curing age, taking into account the influence of water to binder ratio, slag proportion and curing temperature. Modeling the chemical shrinkage 
requires, a comprehensive knowledge of the hydration reactions, which gives the composition of the mixture as a function of time. To validate the model, the computed results of hydration, chemical shrinkage and remained $\mathrm{CH}$ are compared to experimental ones. In this study, different proportions of slag (0\%, 30\%, 50\% and $80 \%)$ are considered. Finally, a sensitivity analysis is proposed in an attempt to examine the influence of certain properties on the hydration and chemical shrinkage and to show the limitations of the model.

\section{Research significance}

Modeling the hydration of the slag-blended cement is important for better understanding of the underlying chemistry and for simulating its microstructure evolution. There are few studies in literature concerning the interaction between slag and pure $\mathrm{CH}$ [16,31]. Richardson [16] investigated the stoichiometry of the reaction between slag and $\mathrm{CH}$ as a function of the temperature and $\mathrm{CH} / \mathrm{slag}$ ratio. The author concluded that, $2.6 \mathrm{~mol}$ of $\mathrm{CH}$ is consumed by each mole of slag reacted. The $\mathrm{C} / \mathrm{S}$ and $\mathrm{A} / \mathrm{S}$ ratios in the product $\mathrm{C}-\mathrm{S}-\mathrm{H}$ were set beforehand to values of 1.42 and 0.046 , respectively. It should be noted that, the determination of the $\mathrm{C} / \mathrm{S}$ and $\mathrm{A} / \mathrm{C}$ (or $\mathrm{A} / \mathrm{S}$ ) ratios in $\mathrm{C}-\mathrm{S}-\mathrm{H}$ is only applicable for the particular used slag proportions in the blended cement. For a given slag composition, the different coefficients must be recalculated through the oxides proportion. Biernacki [31] studied the kinetics of hydration of slag in the presence of Portlondite using the Knudsen model as a function of the temperature and the slag/CH ratio. Biernacki [31] compared the hydration extent between Knudsen's equation [32], Jander's equation [33], Avrami's equation [34] and the experimental data for a given slag/CH ratio and temperature. The author shows that, the Knudsen equation was found to adequately fit both at early age and at later stages of hydration in the presence of $\mathrm{CH}$.

The aim of the present work is to model the hydration of slag blended cement. The kinetics of hydration of pure cement is inspired from the Bernard models $[6,35,36]$. For the slag hydration, Knudsen model [32] was used taking into account the stoichiometry of the reaction between slag and $\mathrm{CH}$ as proposed by Richardson [16]. The Knudsen parameters are identified from the experimental data. The rate constants obtained are then used in Arrhenius plots to obtain the activation energy of the hydration of slag.

\section{Microstructural evolution of the slag-blended cement paste during the hydration process}

\subsection{Hydration kinetics of slag-blended cement components}

\subsubsection{Hydration kinetics of cement}

In order to study the cement paste hydration, the following set of stoichiometric reactions are employed for the four clinker $X$ of Portland cement, i.e., tricalcium silicate $\left(C_{3} S\right)$, dicalcium silicate $\left(C_{2} S\right)$, tricalcium aluminate $\left(C_{3} A\right)$ and tetracalcium aluminate ferrite $\left(C_{4} A F\right)$ (Standard cement chemistry abbreviations are used throughout this paper: $\mathrm{C}=\mathrm{CaO}, \mathrm{S}=\mathrm{SiO}_{2}, \mathrm{~A}=\mathrm{Al}_{2} \mathrm{O}_{3}, \mathrm{M}=\mathrm{Mgo}, \overline{\mathrm{S}}=$ $\mathrm{SO}_{3}, \mathrm{~F}=\mathrm{Fe}_{2} \mathrm{O}_{3}, \mathrm{H}=\mathrm{H}_{2} \mathrm{O}$ ). The hydration of cement is defined below [37-39]:

$\mathrm{C}_{3} \mathrm{~S}+5.3 \mathrm{H} \rightarrow \mathrm{CSH}+1.3 \mathrm{CH}$

$\mathrm{C}_{2} \mathrm{~S}+4.3 \mathrm{H} \rightarrow \mathrm{CSH}+0.3 \mathrm{CH}$

$\mathrm{C}_{3} \mathrm{~A}+3 \mathrm{C} \overline{\mathrm{S}} \mathrm{H}_{2}+26 \mathrm{H} \rightarrow \mathrm{C}_{6} \mathrm{~A}_{3} \mathrm{H}_{32}$

$\mathrm{C}_{4} \mathrm{AF}+3 \mathrm{C} \overline{\mathrm{S}} \mathrm{H}_{2}+30 \mathrm{H} \rightarrow \mathrm{C}_{6} \mathrm{~A}_{3} \mathrm{H}_{32}+\mathrm{CH}+\mathrm{FH}_{3}$

$2 \mathrm{C}_{3} \mathrm{~A}+\mathrm{C}_{6} \mathrm{AS}_{3} \mathrm{H}_{32}+4 \mathrm{H} \rightarrow 3 \mathrm{C}_{4} \mathrm{~A} \overline{\mathrm{S}} \mathrm{H}_{12}$

$2 \mathrm{C}_{4} \mathrm{AF}+\mathrm{C}_{6} \mathrm{AS}_{3} \mathrm{H}_{32}+12 \mathrm{H} \rightarrow 3 \mathrm{C}_{4} \mathrm{~A} \overline{\mathrm{S}} \mathrm{H}_{12}+2 \mathrm{CH}+2 \mathrm{FH}_{3}$

$\mathrm{C}_{3} \mathrm{~A}+6 \mathrm{H} \rightarrow \mathrm{C}_{3}(\mathrm{~A}, \mathrm{~F}) \mathrm{H}_{6}$

$\mathrm{C}_{4} \mathrm{AF}+10 \mathrm{H} \rightarrow \mathrm{C}_{3}(\mathrm{~A}, \mathrm{~F}) \mathrm{H}_{6}+\mathrm{CH}+\mathrm{FH}_{3}$
The hydration of $\mathrm{C}_{3} \mathrm{~S}$ and $\mathrm{C}_{2} \mathrm{~S}$ from the Eqs. (1) and (2) occurs in contact with water, an amorphous gel of the silica calcium hydrate (CSH) and Portlandite $(\mathrm{CH})$, which develops in the pore space. Eqs. (3) and (4) describe the formation of calcium aluminate hydrates from $C_{3} A$ and $C_{3} A F$ in the presence of gypsum, which is added to prevent rapid setting of $C_{3} A$ and $C_{3} A F$. Initially, they react with gypsum to form ettringite $C_{6} A \bar{S}_{3} \mathrm{H}_{32}$ following the Eqs. (3) and (4). After consuming gall gypsum, $\mathrm{C}_{3} \mathrm{~A}$ and $\mathrm{C}_{4} \mathrm{AF}$ react with the formed ettringite to form monosulfoaluminates, Eqs. (5) and (6), respectively. When the ettringite is totally consumed, the $C_{3} A$ and $\mathrm{C}_{4} \mathrm{AF}$ react with Portlandite $\mathrm{CH}$ (one of the products of $\mathrm{C}_{3} \mathrm{~S}$ and $\mathrm{C}_{2} \mathrm{~S}$ hydration) according to Eqs. (5) and (6), respectively.

The cement hydration extent is described by the degree of hydration of each clinker noted $\xi_{\mathrm{C}_{3} \mathrm{~S}}, \xi_{\mathrm{C}_{2} \mathrm{~S}}, \xi_{\mathrm{C}_{3} \mathrm{~A}}$ and $\xi_{\mathrm{C}_{4} \mathrm{AF}}$, respectively. Each clinker has a different hydration kinetics of which will depend on its normalized affinity $\widetilde{A}\left(\xi_{X}\right)$ and its associated characteristic time $\tau_{X}$ associated with the reaction of clinker $X$. The hydration kinetic evolution of each clinker is controlled by induction, nucleation, and diffusion. These kinetic laws can be written in the following dimensionless form $[6,40]$ :

$\tau_{X} \frac{d \xi}{d t}=\widetilde{A}\left(\xi_{X}\right)$

Given the thermal activation of the hydration reaction, the characteristic time depends on the temperature following the Arrhenius concept [6]:

$\tau_{X}(T)=\tau_{X}\left(T_{0}\right) \exp \left[\frac{E_{a X}}{R}\left(\frac{1}{T_{0}}-\frac{1}{T}\right)\right]$

where $E_{a X}$ is the activation energy of the chemical reaction for the clinker $X \cdot R$ is the universal gas constant, and $\tau_{X}\left(T_{0}\right)$ is the characteristic time of the reaction at a constant reference temperature $T_{0}=293 \mathrm{~K}$. Given that the hydration kinetics is accelerated by a smaller fineness due to the greater specific surface area, the characteristic time is given then by [6]:

$\tau_{X}\left(T_{0}, \phi\right)=\frac{\phi_{0}}{\phi} \tau_{X}\left(T_{0}, \phi_{0}\right)$

where $\phi_{0}$ is the reference fineness and is equal to $3602 \mathrm{~cm}^{2} / \mathrm{g}$. The expression of the normalized affinity of each clinker depends on the physical process at stake. According to [6], three stages of the hydration process can be distinguished:

(1) Dissolution of clinker $\left(t<t_{X, 0}\right.$ and $\left.\xi<\xi_{X, 0}\right)$

In this process, because relatively short period, the process can be simulated by a constant reaction rate. The normalized affinity is $\widetilde{A}=1$. The characteristic time $\tau_{X}$ is equal to $t_{X, 0} /$ $\xi_{X, 0}$, where $t_{X, 0}$ is the duration of the induction period, and $\xi_{X, 0}$ is the degree of hydration threshold of clinker $X$ at the end of the dissolution period. For this period at isothermal conditions, i.e., $T=$ const, the hydration kinetic evolution $\xi_{X}$ is written as [7]:

$$
\xi_{X}=\frac{t}{\tau_{X}\left(T_{0}, \phi_{0}\right)} \frac{\phi}{\phi_{0}} \exp \left[\frac{-E_{a X}}{R}\left(\frac{1}{T_{0}}-\frac{1}{T}\right)\right]
$$

(2) Nucleation and growth kinetics $\left(t_{X, 0}<t<\bar{t}_{X}\right.$ and $\left.\xi_{X, 0}<\xi<\bar{\xi}_{X}\right)$ :

For this period the Avrami model is employed [34], reading:

$$
-\ln \left(1-\left(\xi_{X}-\xi_{X, 0}\right)\right)=\left[K \frac{\phi}{\phi_{0}} \exp \left[\frac{-E_{a X}}{R}\left(\frac{1}{T_{0}}-\frac{1}{T}\right)\right]\left(t-t_{X, 0}\right)\right]^{m}
$$

The normalized affinity and the characteristic time of the Avrami model are: 


$$
\begin{aligned}
& \widetilde{A}=\frac{1-\left(\xi_{X}-\xi_{X, 0}\right)}{\left[-\ln \left(1-\left(\xi_{X}-\xi_{X, 0}\right)\right)\right]^{\frac{1}{m}-1}} \\
& \tau_{X}(T, \phi)=\frac{1}{m K} \frac{\phi_{0}}{\phi} \exp \left[\frac{E_{a X}}{R}\left(\frac{1}{T_{0}}-\frac{1}{T}\right)\right]
\end{aligned}
$$

For this period at isothermal conditions, i.e., $T=$ const, the hydration kinetic evolution $\xi_{X}$ is written as:

$$
\xi_{X}=\xi_{X, 0}+1-\exp \left\{-\left[K \frac{\phi}{\phi_{0}} \exp \left[\frac{-E_{a X}}{R}\left(\frac{1}{T_{0}}-\frac{1}{T}\right)\right]\left(t-t_{X, 0}\right)\right]^{m}\right\}
$$

$m$ is the exponent that defines the reaction order, and $K$ is the rate constant and is adjusted from the experimental data carried out during the present work.

(3) Diffusion limited kinetics $\left(t>\bar{t}_{X}\right.$ and $\left.\xi>\bar{\xi}_{X}\right)$ :

The kinetics of the hydration reactions is limited by diffusion of dissolved ions through the layers of hydrates products around the clinker grain. For this period the Fuji and Kondo model is employed [41]. Written in the rate form of kinetic law, the normalized affinity and the characteristic time of this process can be expressed as:

$$
\begin{aligned}
& \widetilde{A}=\frac{(1-\xi)^{2 / 3}}{\left(1-\bar{\xi}_{X}\right)^{1 / 3}-(1-\xi)^{1 / 3}} \\
& \tau_{X}(T, \phi)=\frac{R^{2}}{3 D} \frac{\phi_{0}}{\phi} \exp \left[\frac{E_{a X}}{R}\left(\frac{1}{T_{0}}-\frac{1}{T}\right)\right]
\end{aligned}
$$

where $D$ is a diffusion coefficient (of dimension $[D]=L^{2} / T$ ), and $R$ is the average initial radius of clinker cement. At isothermal conditions, i.e., $T=$ const, the hydration kinetic evolution $\xi_{X}$ for this period is written as [7]:

$$
\xi_{X}=1-\left[-\frac{\left(2 D\left(t-\bar{t}_{X}\right)\right)^{1 / 2}}{R\left\{\exp \left[\frac{-E_{a X}}{R}\left(\frac{1}{T_{0}}-\frac{1}{T}\right)\right]\right\}^{1 / 2}\left(\phi_{0} / \phi\right)^{1 / 2}}+\left(1-\bar{\xi}_{X}\right)^{1 / 3}\right]^{3}
$$

The kinetic parameters used for this process are given in Table 1. All values are determined for a fineness $\phi_{0}=3602 \mathrm{~cm}^{2} / \mathrm{g}$ and an average particle size $R=5 \times 10^{-4} \mathrm{~cm}$.

The hydration degree $\xi_{\text {cem }}(t)$ of cement is obtained from the values of the kinetic $\xi_{X}$ for each clinker determined from the mentioned laws:

$\xi_{\text {cem }}(t)=\frac{\sum_{X} m_{X} \xi_{X}(t)}{\sum_{X} m_{X}}$

where $X \in\left\{C_{3} S, C_{2} S, C_{3} A, C_{4} A F\right\}$ and $m_{X}$ are the mass fractions of the clinker $X$ phases.

\subsubsection{Hydration kinetics of slag}

Hydration products in the slag-blended cement paste comprise those products from both cement and slag hydrations except that the amount of $\mathrm{CH}$ produced by the cement hydration is considered to be available for the slag hydration [29]. Five oxides, namely C, S, A, M and $\bar{S}$, are selected among the oxides constitutions of slag. They are the most abundant oxides in the slag and are combined in the selected products. Molar proportions were used to study the hydration process in the presence of Portlandite $\mathrm{CH}$. Richardson [16] have proposed the following chemical reaction for the slag/CH reaction:

$$
\begin{aligned}
\mathrm{C}_{7.88} \mathrm{~S}_{7.39} \mathrm{AM}_{3}+n_{\mathrm{CH}} \mathrm{CH}+n_{\mathrm{H}} \mathrm{H} \rightarrow & n_{\mathrm{C}-\mathrm{S}-\mathrm{H}} \mathrm{C}_{(\mathrm{C} / \mathrm{S})} \mathrm{SH}_{x} \mathrm{~A}_{(\mathrm{A} / \mathrm{S})} \\
& +n_{\mathrm{AH}} \mathrm{C}_{4.6} \mathrm{AH}_{d}
\end{aligned}
$$

where $n_{\mathrm{CH}}$ and $n_{\mathrm{H}}$ are the stoichiometric coefficients of the Portlandite $(\mathrm{CH})$ and water $(\mathrm{H})$ involved the slag hydration, respectively. $n_{\mathrm{C}-\mathrm{S}-\mathrm{H}}$ is the stoichiometric coefficients of the product $\mathrm{C}_{(\mathrm{C} / \mathrm{S})} \mathrm{SH}_{x} \mathrm{~A}_{(\mathrm{A} / \mathrm{S})}$ namely C-S-H. $x$ is the $\mathrm{H} / \mathrm{S}$ ratio in $\mathrm{C}-\mathrm{S}-\mathrm{H} . n_{\mathrm{AH}}$ is the stoichiometric coefficients of the product $\mathrm{C}_{4.6} \mathrm{AH}_{d}$ namely $\mathrm{AH}$. So, $n_{C-} S_{-H}=7.39$. From Richardson [16], $2.6 \mathrm{~mol}$ of $\mathrm{CH}$ are consumed by each mole of slag reacted. The $\mathrm{C} / \mathrm{S}$ and $\mathrm{A} / \mathrm{S}$ ratios in $\mathrm{C}-\mathrm{S}-\mathrm{H}$ was set beforehand to a values of 1.42 and 0.046 , respectively. A molar balance calculation between the two sides of Eq. (21) leads to $n_{\mathrm{AH}}=0.66$. It should be noted that, the resulting stoichiometric coefficients and empirical formulas are only applicable for particular slag composition. For a given slag, the different coefficients must be recalculated through the oxides proportion. In the present study, the proprieties of $\mathrm{C}_{4.6} \mathrm{AH}_{d}$ are considered close to the $\mathrm{C}_{4} \mathrm{AH}_{d}$ presented by Chen [12] with $d=13$.

The water-binding characteristic of $\mathrm{C}-\mathrm{S}-\mathrm{H}$ is complex. It is still subject of many researches. $\mathrm{C}-\mathrm{S}-\mathrm{H}$ has a layer structure and comprises pores sizing in a wide range, which may be partially or completely filled with water. The total porosity is also influenced by the composition of $\mathrm{C}-\mathrm{S}-\mathrm{H}$ as well [42].

Steinour [43] shows that, at $105^{\circ} \mathrm{C}$ in a carbonation-free environment, for $\mathrm{C}-\mathrm{S}-\mathrm{H}$ with low $\mathrm{C} / \mathrm{S}$ ratios $(1.0-1.1)$, the measured $\mathrm{H} / \mathrm{S}$ ratios in $\mathrm{C}-\mathrm{S}-\mathrm{H}$ ranging between 1 and 1.33 . The author concluded that the water retained in $\mathrm{C}-\mathrm{S}-\mathrm{H}$ at $105^{\circ} \mathrm{C}$ is loosely correlated to its $\mathrm{C} / \mathrm{S}$ ratio and might be closer to a constant value.

Based on the work of Brouwers [42,44], the H/S ratio in $\mathrm{C}-\mathrm{S}-\mathrm{H}$ can be expressed with $x=C / S+0.8$ at $80 \% \mathrm{RH}$ [12], and $x=C / S+1.5$ in the saturated state [12]. It should be noted that, initially the state is saturated and the relative humidity decreases very quickly to stabilize at around $70-80 \%$. In this study, the experiments were carried out at room temperature, and the relative humidity keeps less than $100 \%$. So, the $\mathrm{H} / \mathrm{S}$ ratio $(x)$ in $\mathrm{C}-\mathrm{S}-\mathrm{H}$ is deduced and is equal to $\mathrm{C} / \mathrm{S}+0.8$ [12].

Because the reaction of slag is treated separately from that of ordinary Portland cement hydration, the slag hydration extent is modeled using the Knudsen model [32]:

$\xi_{s l g}(t)=\xi_{s l g}^{u} \frac{k\left(t-t_{0}\right)^{n}}{1+k\left(t-t_{0}\right)^{n}}$

where $\xi_{s l g} / \xi_{s l g}^{u}$ is the reaction extent, which is the property $\left(\xi_{s l g}\right) /$ maximum value of the property $\left(\xi_{s l g}^{u}\right), k$ is a rate constant, $t$ is the time, $t_{0}$ is the induction time, and $n$ is the reaction exponent. The temperature dependence of the rate constant is described using the Arrhenius equation:

$k=k_{0} e^{-E / R T}$

where $k_{0}$ is the pre-exponential factor, $E$ is the activation energy, $R$ is the gas constant, and $T$ is the absolute temperature. The Knudsen exponent $n$ is equal to 1 and $t_{0}$ was set at 0 since no significant induction period was observed.

The overall hydration degree $\xi(t)$ of slag-blended cement is obtained from the values of the kinetic for the cement $\xi_{\text {cem }}(t)$ and the slag $\xi_{\text {slg }}(t)$ using the following relation as a function of the mass of cement $m_{\text {cem }}$ and the one of slag $m_{\text {slg: }}$ :

$\xi(t)=\frac{m_{\text {cem }}}{m_{\text {cem }}+m_{\text {slg }}} \xi_{\text {cem }}(t)+\frac{m_{\text {slg }}}{m_{\text {cem }}+m_{\text {slg }}} \xi_{\text {slg }}(t)$

\subsection{Calculation of the volume of the slag-blended cement phases}

The volume of the cement phases is calculated in the same way of the slag. From hydration kinetics model $\xi_{X}$ of each clinker phase, 
the volume of the phases involved in the micromechanics $V_{X}$ is linearly related to the clinker hydration degree, and it is calculated as:

$V_{X}(t)=V_{X}^{0}\left(1-\xi_{X}(t)\right)$

where $V_{X}^{0}$ is the initial volume of the clinker phases in the cement. The volume of water is determined as:

$\left.V_{w}(t)=V_{w}^{0}-\Sigma_{X} V_{w}^{X} \xi_{X}(t)\right)$

$V_{w}^{0}$ is the initial volume of water, and $V_{w}^{X}$ is the volume of water that is consumed by the clinker hydration, and is determined as:

$V_{w}^{X}=V_{c}^{0} \Theta_{w}^{X} \frac{\bar{\rho}_{X} / M_{X}}{\rho_{w} / M_{w}}$

where $V_{c}^{0}$ is the initial volume of cement paste, $\Theta_{w}^{X}=n_{w} / n_{X}$ denotes the number of moles of water $n_{w}$ consumed during the hydration of mole $n_{X}=1$ of clinker phase $X, M_{X}$ is the molar mass of the clinker phase $X . \bar{\rho}_{X}$ is its apparent mass, $\rho_{w}$ and $M_{w}$ are the density and molar mass of water, respectively. The apparent density is given by:

$\bar{\rho}_{X}=\rho_{c} f_{X}$

where $\rho_{c}$ is the density of cement, $f_{X}$ if the volume fraction of clinker $X$.

The remaining volume of gypsum $\mathrm{C} \overline{\mathrm{S}} \mathrm{H}_{2}$ is calculated by the same way of the remaining volume water:

$V_{\mathrm{C}_{\overline{\mathrm{S}}}}(t)=V_{\mathrm{CS}_{2}}^{0}-\Sigma_{X} V_{\mathrm{C}_{\bar{S}}}^{X} \xi_{X}(t)$

$V_{\mathrm{CS}^{2} \mathrm{H}_{2}}^{0}$ is the initial volume of gypsum, and $V_{\overline{\mathrm{CS}} \mathrm{H}_{2}}^{X}$ is the volume of gypsum that is consumed in the clinker hydration, and it is determined in the same way as water:

$V_{\mathrm{C} \bar{S}_{2}}^{X}=V_{c}^{0} \Theta_{\bar{C}_{\bar{S}} H_{2}}^{X} \frac{\bar{\rho}_{X} / M_{X}}{\rho_{\bar{C}_{\mathrm{S}_{2}}} / M_{\bar{C} \mathrm{~S}_{2}}}$

$\Theta_{\mathrm{C} \overline{\mathrm{S}} \mathrm{H}_{2}}^{X}=n_{\mathrm{C} \overline{\mathrm{S}} \mathrm{H}_{2}} / n_{X}$ is the number of moles of gypsum $n_{\mathrm{C} \overline{\mathrm{S}} \mathrm{H}_{2}}$ consumed during the hydration of $n_{X}=1 \mathrm{~mol}$ of clinker phase $X, \rho_{\overline{\mathrm{S}}_{\mathrm{H}}}$ and $M_{\mathrm{C} \overline{\mathrm{S}} \mathrm{H}_{2}}$ are the density and molar mass of gypsum $\left(\mathrm{C}_{\overline{\mathrm{S}}} \mathrm{H}_{2}\right)$, respectively.

During the hydration of $\mathrm{C}_{3} \mathrm{~S}$ and $\mathrm{C}_{2} \mathrm{~S}$, two types of CSH are formed, the first is the low-density CSHa phase, which corresponds to the outer products, and the second is the high-density CSHb phase, which corresponds to the inner products. The volume for each phases is calculated as the following equation:

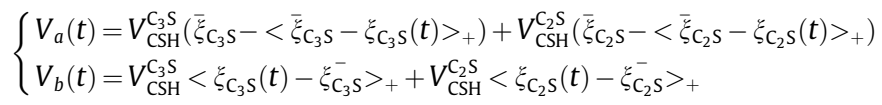

where $V_{\mathrm{CSH}}^{\mathrm{C}_{3} \mathrm{~S}}$ and $V_{\mathrm{CSH}}^{\mathrm{C}_{2} \mathrm{~S}}$ are the volume occupied by the reaction products of the hydration of $\mathrm{C}_{3} \mathrm{~S}$ and $\mathrm{C}_{2} \mathrm{~S}$ in the $\mathrm{CSH}$, and are calculated as:

$$
\left\{\begin{array}{l}
V_{\mathrm{CSH}}^{\mathrm{C}_{3} \mathrm{~S}}=V_{c}^{0} \Theta_{\mathrm{CSH}}^{\mathrm{C}_{3} \mathrm{~S}} \frac{\bar{\rho}_{\mathrm{C}_{3} \mathrm{~S}} / M_{\mathrm{C}_{3} \mathrm{~S}}}{\rho_{\mathrm{CSH}} / M_{\mathrm{CSH}}} \\
V_{\mathrm{CSH}}^{\mathrm{C}_{2} \mathrm{~S}}=V_{c}^{0} \Theta_{\mathrm{CSH}}^{\mathrm{C}_{2} \mathrm{~S}} \frac{\bar{\rho}_{\mathrm{C}_{2} \mathrm{~S}} / M_{\mathrm{C}_{2} \mathrm{~S}}}{\rho_{\mathrm{CSH}} / M_{\mathrm{CSH}}}
\end{array}\right.
$$

$\Theta_{\mathrm{CSH}}^{\mathrm{C}_{3} \mathrm{~S}}=n_{\mathrm{CSH}} / n_{\mathrm{C}_{3} \mathrm{~S}}$ and $\Theta_{\mathrm{CSH}}^{\mathrm{C}_{2} \mathrm{~S}}=n_{\mathrm{CSH}} / n_{\mathrm{C}_{2} \mathrm{~S}}$, are the number of moles $n_{\mathrm{CSH}}$ of $\mathrm{CSH}$ formed during the hydration of $n_{\mathrm{C}_{3} \mathrm{~S}}=1$ mole of clinker phase $C_{3} S$ and $n_{\mathrm{C}_{2} \mathrm{~S}}=1$ of $\mathrm{C}_{2} \mathrm{~S}$, respectively. $\rho_{\mathrm{CSH}}$ and $M_{\mathrm{CSH}}$ are the density and mass molar of $\mathrm{CSH}$, respectively. The total volume of $\mathrm{CSH}$ is given as:

$V_{\mathrm{CSH}}=V_{\mathrm{CSH}}^{\mathrm{C}_{3} \mathrm{~S}}+V_{\mathrm{CSH}}^{\mathrm{C}_{2} \mathrm{~S}}$

Analogously, the volume occupied by the product element noted $i$, is a combination of the reaction products of the hydration of each clinker $X$ and is determined as the following equation:

$V_{i}(t)=\Sigma_{X} V_{i}^{X} \xi_{X}(t)$ and the consumed volume during the clinker hydration reaction is determined as:

$V_{i}^{X}=V_{c}^{0} \Theta_{i}^{X} \frac{\bar{\rho}_{X} / M_{X}}{\rho_{i} / M_{i}}$

$i \in\left\{\mathrm{CH}, \mathrm{C}_{6} \mathrm{~A} \overline{\mathrm{S}}_{3} \mathrm{H}_{32}, \mathrm{C}_{4} \mathrm{~A} \overline{\mathrm{S}} \mathrm{H}_{12}, C_{3}(\mathrm{~A}, \mathrm{~F}) \mathrm{H}_{6}, \mathrm{FH}_{3}\right\}, \Theta_{i}^{X}=n_{i} / n_{X}$ is the number of moles of product $i$ created during the hydration of $n_{X}=1 \mathrm{~mol}$ of clinker phase $X, M_{i}$ and $\rho_{i}$ are the molar mass and density of product $i$, respectively.

During the hydration of the clinker phases, capillary voids are created due to a negative volume balance (or chemical shrinkage) between reactant and product phases involved in the hydration reactions of the clinker phases:

$\left.V_{V}(t)=-\Sigma_{X} V_{V}^{X} \xi_{X}(t)\right)$

with:

$V_{V}^{X}=V_{c}^{0} \Theta_{V}^{X} f_{X}$

$\Theta_{V}^{X}=n_{V} / n_{X}$ is the number of moles of void $V$ created during the hydration of $n_{X}=1 \mathrm{~mol}$ of clinker phase $X$.

All data, used for the calculation of the volume fractions are given in the Tables $1-3$.

The volume evolution of slag is linearly related to the slag hydration degree:

$V_{s l g}(t)=V_{s l g}^{0}\left(1-\xi_{s l g}(t)\right)$

where $V_{s l g}^{0}$ is the initial volume of slag. The volume of hydration products $\mathrm{C}-\mathrm{S}-\mathrm{H}$ and $\mathrm{C}_{4.6} \mathrm{AH}_{d}$ created during the slag hydration is calculated as:

Table 1

Reaction kinetic model parameters of the four clinker hydration reactions [6,45].

\begin{tabular}{llllllll}
\hline Clinker $(X)$ & $w / c$ & $\tau_{X}\left(T_{0}, \phi_{0}\right)$ & $\mathrm{m}$ & $\xi_{X, 0}$ & $D\left[\mathrm{~cm}^{2} / \mathrm{h}\right]$ & $\bar{t}_{X}$ & $E_{a X} / R[\mathrm{~K}]$ \\
\hline $\mathrm{C}_{3} \mathrm{~S}$ & 0.3 & 13.5 & 1.86 & 0.02 & $0.42 \times 10^{-10}$ & 0.60 & 4500 \\
& 0.5 & 11.9 & 1.72 & & $2.64 \times 10^{-10}$ & & \\
& 0.7 & 10.5 & 1.66 & & $15.6 \times 10^{-10}$ & & \\
$\mathrm{C}_{2} \mathrm{~S}$ & 0.3 & 71.2 & 1.10 & 0.00 & $6.64 \times 10^{-13}$ & 0.60 & 2500 \\
& 0.5 & 60.9 & 0.96 & & & & \\
& 0.7 & 58.6 & 0.84 & & & & \\
$\mathrm{C}_{3} \mathrm{~A}$ & 0.3 & 57.7 & 1.14 & 0.04 & $2.64 \times 10^{-10}$ & 0.60 & 5500 \\
& 0.5 & 49.2 & 1.00 & & & & \\
& 0.7 & 35.9 & 0.86 & & & & \\
$\mathrm{C}_{4} \mathrm{~F}$ & 0.3 & 27.0 & 2.44 & 0.40 & $0.42 \times 10^{-10}$ & 0.60 & 4200 \\
& 0.5 & 21.4 & 2.30 & & $2.64 \times 10^{-10}$ & & \\
& 0.7 & 14.3 & 2.16 & & $15.6 \times 10^{-10}$ & & \\
\hline
\end{tabular}

Table 2

Parameters for the determination of the volume fractions.

\begin{tabular}{lllll}
\hline Clinker $(X)$ & $\mathrm{C}_{3} \mathrm{~S}$ & $\mathrm{C}_{2} \mathrm{~S}$ & $\mathrm{C}_{3} \mathrm{~A}$ & $\mathrm{C}_{4} \mathrm{AF}$ \\
\hline $\bar{\rho}_{X}$ & $\rho_{c} f_{\mathrm{C}_{3} \mathrm{~S}}$ & $\rho_{c} f_{\mathrm{C}_{2} \mathrm{~S}}$ & $\rho_{c} f_{\mathrm{C}_{3} \mathrm{~A}}$ & $\rho_{c} f_{\mathrm{C}_{4} \mathrm{AF}}$ \\
$\Theta_{w}^{X}$ & 5.3 & 4.3 & 26 & 30 \\
$\Theta_{w}^{X}$ (all gypsum consumed) & 5.3 & 4.3 & 4 & 12 \\
$\Theta_{w}^{X}$ (all ettringite consumed) & 5.3 & 4.3 & 6 & 10 \\
$\Theta_{\mathrm{C} \overline{\mathrm{S}} \mathrm{H}_{2}}^{X}$ & 0 & 0 & 3 & 3 \\
$\Theta_{\mathrm{CSH}}^{X}$ & 1 & 1 & 0 & 0 \\
$\Theta_{\mathrm{CH}}^{X}$ & 1.3 & 0.3 & 0 & 1 \\
$\Theta_{\mathrm{C}_{6} \mathrm{~A} \overline{\mathrm{S}}_{3} \mathrm{H}_{32}}^{X}$ & 0 & 0 & 1 & 1 \\
$\Theta_{\mathrm{C}_{4} \mathrm{~A} \bar{S}_{12}}^{X}$ & 0 & 0 & $3 / 2$ & $3 / 2$ \\
$\Theta_{\mathrm{C}_{3}(\mathrm{~A}, \mathrm{~F}) \mathrm{H}_{6}}^{X}$ & 0 & 0 & 1 & 1 \\
$\Theta_{\mathrm{FH}}^{X}$ & 0 & 0 & 0 & 1 \\
$\Theta_{V}^{X}[6]$ & -0.073 & -0.077 & -0.077 & -0.077 \\
\hline
\end{tabular}


Table 3

Molar masses and densities of the different phases given in cement paste [6,7].

\begin{tabular}{|c|c|c|c|c|c|}
\hline Clinker $(X)$ & Molar mass $M(\mathrm{~g} / \mathrm{mol})$ & Density $\rho\left(\mathrm{g} / \mathrm{cm}^{3}\right)$ & Clinker $(X)$ & Molar mass $M(\mathrm{~g} / \mathrm{mol})$ & Density $\rho\left(\mathrm{g} / \mathrm{cm}^{3}\right)$ \\
\hline $\mathrm{C}-\mathrm{S}-\mathrm{H}$ & Various & Various (Eq. (40)) & Water $H$ & 18 & 1 \\
\hline $\mathrm{C}_{4} \mathrm{AH}_{d=13}$ & 668.4 & 1.80 & $\mathrm{FH}_{3}$ & 106.9 & 3 \\
\hline $\mathrm{C}_{3} \mathrm{~S}$ & 228.32 & 3.15 & $\mathrm{CS} \mathrm{H}_{2}$ & 172 & 2.32 \\
\hline $\mathrm{C}_{2} \mathrm{~S}$ & 172.24 & 3.28 & $\mathrm{CSH}$ & 227.2 & 2.04 \\
\hline $\mathrm{C}_{3} \mathrm{~A}$ & 270.20 & 3.03 & $\mathrm{CH}$ & 74 & 2.24 \\
\hline $\mathrm{C}_{4} \mathrm{AF}$ & 430.12 & 3.73 & $\mathrm{C}_{6} \mathrm{AS}_{3} \mathrm{H}_{32}$ & 1255 & 1.75 \\
\hline $\mathrm{C}_{4} \mathrm{~A} \overline{\mathrm{S}} \mathrm{H}_{12}$ & 623 & 1.99 & $C_{3}(A, F) H_{6}$ & 407.0 & 2.67 \\
\hline
\end{tabular}

$$
\left\{\begin{array}{l}
V_{\mathrm{C}-\mathrm{S}-\mathrm{H}}^{s l g}(t)=V_{s l g}^{0} \xi_{\text {slg }}(t) n_{\mathrm{C}-\mathrm{S}-\mathrm{H}} \frac{\rho_{\text {slg }} / M_{\text {slg }}}{\rho_{\mathrm{C}-\mathrm{S}-\mathrm{H}} / \mathrm{M}_{\mathrm{C}-\mathrm{S}-\mathrm{H}}} \\
V_{\mathrm{C}_{4.6} \mathrm{sg} \mathrm{AH}_{13}}(t)=V_{s l g}^{0} \xi_{\text {slg }}(t) n_{\mathrm{C}_{4.6} \mathrm{AH}_{13}} \frac{\rho_{\text {slg }} / M_{\text {slg }}}{\rho_{\mathrm{C}_{4.6} \mathrm{AH}_{13} / M_{\mathrm{C}_{4.6}} \mathrm{AH}_{13}}}
\end{array}\right.
$$

$\rho_{\text {slg, }}, \rho_{\mathrm{C}-\mathrm{S}-\mathrm{H}}$ and $\rho_{\mathrm{C}_{4} \mathrm{AH}_{d}}$ are the densities of slag, $\mathrm{C}-\mathrm{S}-\mathrm{H}$ and $\mathrm{C}_{4} \mathrm{AH}_{13}$, respectively. $M_{s l g}, M_{\mathrm{C}-\mathrm{S}-\mathrm{H}}$ and $M_{\mathrm{C}_{4.6} \mathrm{AH}_{13}}$ are the molar mass of slag, $\mathrm{C}-\mathrm{S}-\mathrm{H}$ and $\mathrm{C}_{4} \mathrm{AH}_{13}$, respectively. In this study, the physical properties of $\mathrm{C}-\mathrm{S}-\mathrm{H}$ with various $C / S$ and $A / S$ ratios are calculated using the model proposed by Brouwers [46]. The density of $\mathrm{C}-\mathrm{S}-\mathrm{H}$ is calculated as:

$\rho_{\mathrm{C}-\mathrm{S}-\mathrm{H}}=\frac{87.12+74.10(\mathrm{C} / \mathrm{S})}{38.42+33.05(C / S)}$

in which the molar mass of slag and C-S-H $\left(M_{s l g}, M_{\mathrm{C}-\mathrm{S}-\mathrm{H}}\right)$ can readily be calculated from their compositions. The volume of water and Portlandite $\mathrm{CH}$ consumed by the slag hydration is determined in the same way:

$$
\left\{\begin{array}{l}
V_{w}^{s l g}(t)=V_{s l g}^{0} \xi_{s l g}(t) n_{\mathrm{H}} \frac{\rho_{s l g} / M_{s l g}}{\rho_{w} / M_{w}} \\
V_{\mathrm{CH}}^{s l g}(t)=V_{s l g}^{0} \xi_{s l g}(t) n_{\mathrm{CH}} \frac{\rho_{\text {slg }} / M_{\text {slg }}}{\rho_{\mathrm{CH}} / M_{\mathrm{CH}}}
\end{array}\right.
$$

$\rho_{w}, \rho_{C H}$ and $M_{w}$ and $M_{C H}$ are the density and molar mass of water and $\mathrm{CH}$, respectively.

The remaining volume of water and Portlandite $\mathrm{CH}$ during the hydration of slag-blended cement is then calculated as:

$$
\left\{\begin{array}{l}
V_{w}(t)=V_{w}^{0}-V_{w}^{c e m}(t)-V_{w}^{s l g}(t) \\
V_{\mathrm{CH}}(t)=V_{\mathrm{CH}}^{c e m}(t)-V_{\mathrm{CH}}^{s l g}(t)
\end{array}\right.
$$

$V_{w}^{\text {cement }}$ is the volume of water consumed by the hydration of cement (Eqs. (26) and (27)), $V_{\mathrm{CH}}^{\text {cement }}$ is the volume of $\mathrm{CH}$ produced by the hydration of cement (Eq. (35)). The total volume $V(t)$ is calculated as:

$$
\begin{aligned}
& V(t)=\underbrace{\Sigma_{X} V_{X}(t)+V_{w}(t)+V_{\bar{C}_{\mathrm{H}_{2}}}(t)+V_{\text {slg }}(t)}_{\text {Reactants }} \\
& +\underbrace{V_{\mathrm{CSH}}(t)+V_{\mathrm{CSH}}(t)+V_{\mathrm{C}_{6} \mathrm{~A} \overline{\mathrm{S}}_{3} \mathrm{H}_{32}}(t)+V_{\mathrm{C}_{4} \mathrm{~A} \overline{\mathrm{S}} \mathrm{H}_{12}}(t)+V_{\mathrm{C}_{3}(\mathrm{~A}, \mathrm{~F}) \mathrm{H}_{6}}(t)+V_{\mathrm{FH}_{3}}(t)+V_{V}(t)}_{\text {Cement hydration products }} \\
& +\underbrace{V_{\mathrm{C}-\mathrm{S}-\mathrm{H}}^{\text {slg }}(t)+V_{\mathrm{C}_{4} \mathrm{AH}_{13}}^{\text {slg }}(t)}_{\text {Slag hydration products }}
\end{aligned}
$$

\subsection{Calculation of the chemical shrinkage at early-age}

The chemical shrinkage is the volume reduction of the paste due to the consequence of the chemical reaction of the reactant and water. Generally, the total volume of the reaction product is smaller than that of the initial one. Chemical shrinkages of the slag-blended cements are predicted using the physical properties of the hydration reactants and products. The chemical shrinkage is determined as:

$\Psi(t)=-\frac{V(t)-V^{0}}{m^{0}}$

where $V^{0}$ is the initial volume, and is equal to the sum of slag, cement and water one. $m^{0}$ is the initial cement mass of cement and slag.

\section{Experimental programs}

\subsection{Materials}

The Portland cement used is a CEM I $52.5 \mathrm{~N}$ (Le Havre plant, Lafarge). The Bogue's composition is $67.50 \%$ of $C_{3} S, 12.21 \%$ of $C_{2} S$, $8.81 \%$ of $\mathrm{C}_{3} \mathrm{~A}, 7.97 \%$ of $\mathrm{C}_{4} \mathrm{AF}$ and $3.30 \%$ of $\mathrm{C} \overline{\mathrm{S}} \mathrm{H}_{2}$. Its Blaine fineness was $3460 \mathrm{~cm}^{2} / \mathrm{g}$ and it contained $3.3 \%$ of gypsum. The blast furnace slag ground is provided by the company ECOCEM (plant Aix en Provence). The composition of the cement and slag is given in Table 4 . The water to binder $(w / b)$ ratio is equal to 0.32 . To assess the effect of slag at $20^{\circ} \mathrm{C}$, four systems were investigated, pure cement and slag cement containing $30 \%, 50 \%$ and $80 \%$ slag by weight. The paste is prepared in a mixer of $20 \mathrm{~L}$ capacity. The solid constituents are firstly mixed for $30 \mathrm{~s}$. Then, the mixing water is introduced and mixing is continued for $90 \mathrm{~s}$ at low speed and $90 \mathrm{~s}$ at high speed.

Table 4

Compositions of cement and slag.

\begin{tabular}{llllll}
\hline Constituents & Cement (\%) & Slag (\%) & Constituents & Cement (\%) & Slag (\%) \\
\hline $\mathrm{SiO}_{2}$ & 21.39 & 4.49 & $\mathrm{TiO}_{2}$ & 0.16 & 0.88 \\
$\mathrm{Al}_{2} \mathrm{O}_{3}$ & 3.66 & 13.19 & $\mathrm{~K}_{2} \mathrm{O}$ & 0.28 & 0.54 \\
$\mathrm{Fe}_{2} \mathrm{O}_{3}$ & 4.25 & 0.40 & $\mathrm{Na}_{2} \mathrm{O}$ & $\mathrm{SO}_{3}$ & 2.63 \\
$\mathrm{CaO}$ & 64.58 & 41.03 & $\mathrm{MnO}$ & 0.13 & 0.10 \\
$\mathrm{MgO}$ & 0.96 & 8.21 & & & 0.40 \\
Density $\left(\mathrm{kg} / \mathrm{m}^{3}\right)$ & 3200 & 2890 & & & \\
\hline
\end{tabular}




\subsection{Testing methods}

\subsubsection{Heat of hydration}

A microcalorimeter TAM Air isothermal is used to measure the heat flux of reaction and the reaction kinetics of binding at the early age. For each binder paste, two samples of approximately $4 \mathrm{~g}$ are collected at the end of mixing, weighed $(0.01 \mathrm{~g})$ and introduced into flacons. The sealed flacons are then placed in the device and the acquisition is started. Each test is conducted in the first 5 days of hydration. The first flow measurement is performed about 10 min after mixing.

\subsubsection{Chemical shrinkage}

Chemical shrinkage is measured using the volume method by hydrostatic weighing [4]. From the end of mixing, two samples of 4-5 g are introduced into two different flacons. The remaining volume of these bottles is then filled with desecrated water, while avoiding disruption of the samples. Then, each flacon is immersed in water and suspended by a nylon thread to a balance of $0.001 \mathrm{~g}$ of precision. The experimental device is placed in a room conditioned at $20 \pm 2{ }^{\circ} \mathrm{C}$. The first weight gain is made about $15 \mathrm{~min}$ after mixing. The acquisition is done automatically for $140 \mathrm{~h}$.

\subsubsection{Thermo-gravimetric analysis}

A TGA/DSC of Mettler Toledo was used to measure the evolution of the weight versus the temperature. The sample with a mass between 200 and $250 \mathrm{mg}$ is subjected to a temperature of up to $1050{ }^{\circ} \mathrm{C}$. The evolution of the mass of the sample and that of its derivative versus temperature allows determining the material composition.

\section{Results and discussion}

\subsection{Experimental results: Heat of hydration and chemical shrinkage}

Fig. 1 shows the evolution of the heat of hydration as a function of time for the four used systems. According to this figure, the increase of slag addition in the mixture decreases the heat of hydration. It can be observed that, the increasing of the slag causes a notably decrease to the heat of hydration. After $140 \mathrm{~h}$ of curing, the total heat decreased from $260 \mathrm{~J} / \mathrm{g}$ for the pure cement to $100 \mathrm{~J} / \mathrm{g}$ for the binder with $80 \%$ of slag. The presence of the slag contributes clearly to the reduction of the heat of hydration which is very beneficial for mass concrete to minimize the risk of cracking. This phenomenon may have two explanations: the dilution effect of the supplementary cementitious materials [9,47] and the

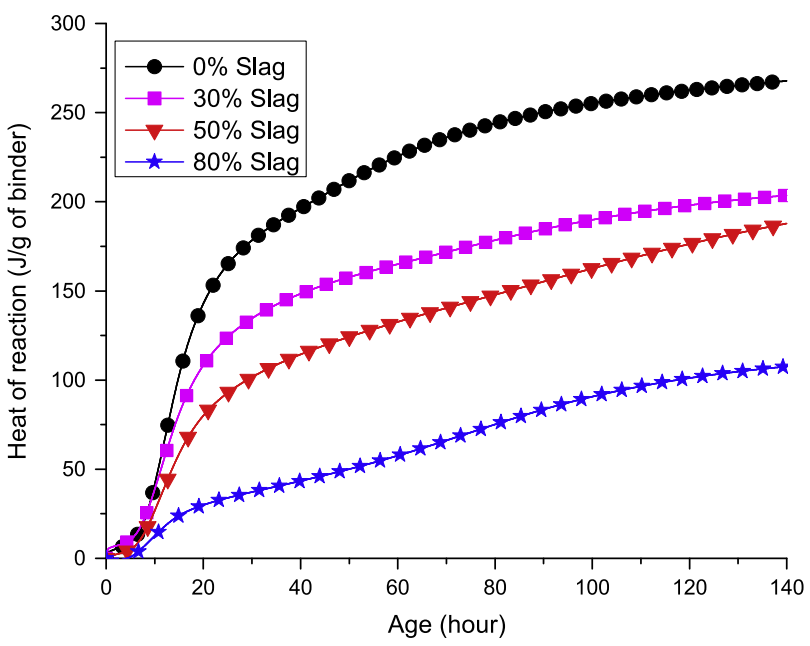

Fig. 1. Heat of reaction of binders with $w / b=0.32$ for various slag proportions.

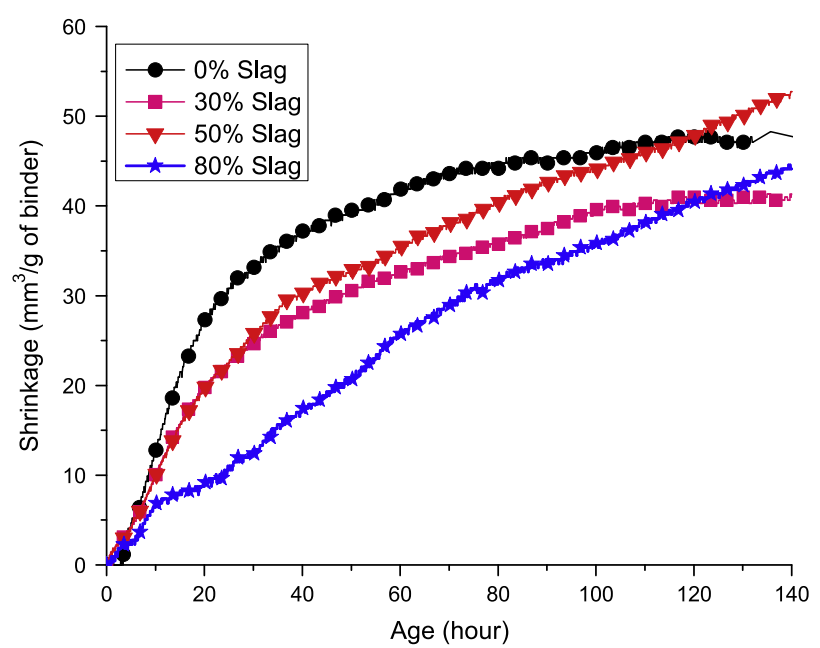

Fig. 2. Chemical shrinkage of binder with $w / b=0.32$ for various slag proportions.

pozzolanic reactions of the slag which release less heat than Portland cement $[15,48]$. Escalante-Garcia and Sharp [9] suggested that the cement hydration in the binder was accelerated. Indeed increasing the slag content causes more water available for Portland cement hydration in the blended cement. The evolution of the heat of hydration as a function of the slag content is close to that found by Wang et al. [49] for $25 \%$ and $45 \%$ slag at $23{ }^{\circ} \mathrm{C}$ and for a water to binder ratio is 0.35 .

The results for the chemical shrinkage are presented in Fig. 2. The chemical shrinkage is a function of the slag content. The effect of slag on chemical shrinkage depended on its dosage. For binary binder pastes with $0 \%$ and $30 \%$ of slag, the curves showed a rapid increase during the first $20 \mathrm{~h}$, due to the hydration of Portland cement, followed by a slow deformation phase. The shrinkage of pastes with $50 \%$ and $80 \%$ of slag presented a similar evolution to that of the paste with $30 \%$ of slag during the first hours. At $24 \mathrm{~h}$, the pastes with $30 \%, 50 \%$ and $80 \%$ slag, exhibited chemical shrinkage values that were lower by $30 \%, 26 \%$ and $57 \%$, respectively than that of the reference paste. Then, the chemical shrinkage evolution rate of the pastes with slag increased. At $140 \mathrm{~h}$, the difference with the reference paste was reduced to $14 \%$ and $7 \%$ for the binder with $30 \%$ and $80 \%$ slag, respectively, while the paste of the binder with $50 \%$ slag even showed higher chemical shrinkage than that of the control binder. This acceleration resulted in a curve crossing between 80 and $120 h$ of hydration and could be explained by the beginning of the slag reactions, which generated additional chemical shrinkage $[15,50]$. It might be possible that the same phenomena occurs in fly ash-cement mixes [51].

\subsection{Identification of the slag hydration parameters}

The modeling of the slag hydration in the blended cement is more complex than that of the cement. The hydration of slag depends on several important parameters such as: the slag reactivity, the pore solution composition, the activators such as sulfates and Portlandite $(\mathrm{CH})$, temperature and $w / b$ ratio.

It should be noted that, the identification of the parameters governing the slag hydration in the blended cement is not simple, especially because the chemical equations between the different parameters in relation to the slag hydration are not defined, and they are more difficult to establish. It is therefore necessary to make assumptions about the parameters governing the slag hydration. In the present work, the Knudsen model is used to predict the hydration degree of slag in the blended cement, the different parameters must be identified from experimental data. Due to lack 
of information, the Knudsen parameters are considered only as a function of the slag/cement ratio. The regression analysis with the experimental data yields a linear relation between the Knudsen

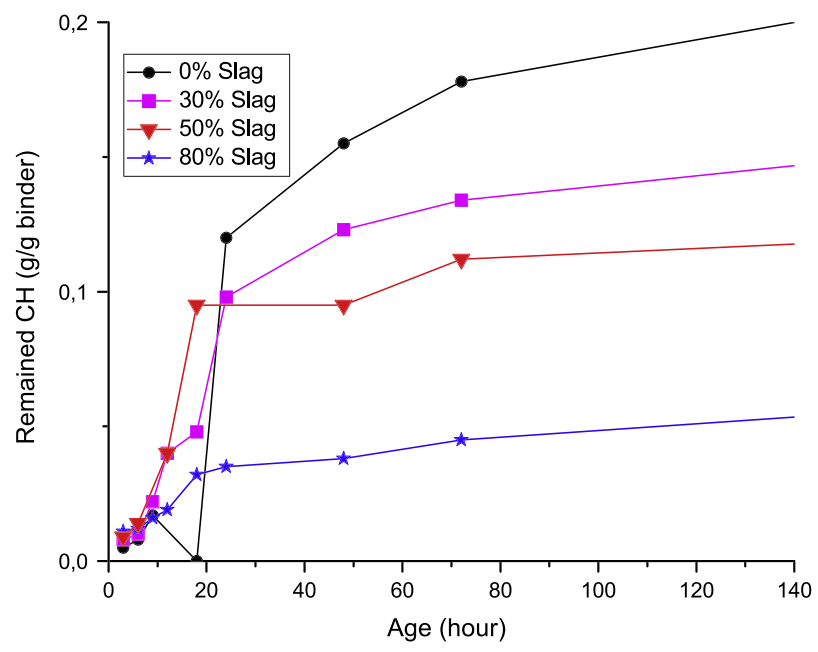

Fig. 3. Remained $\mathrm{CH}$ (g/g binder) with $w / b=0.32$ for various slag proportion.

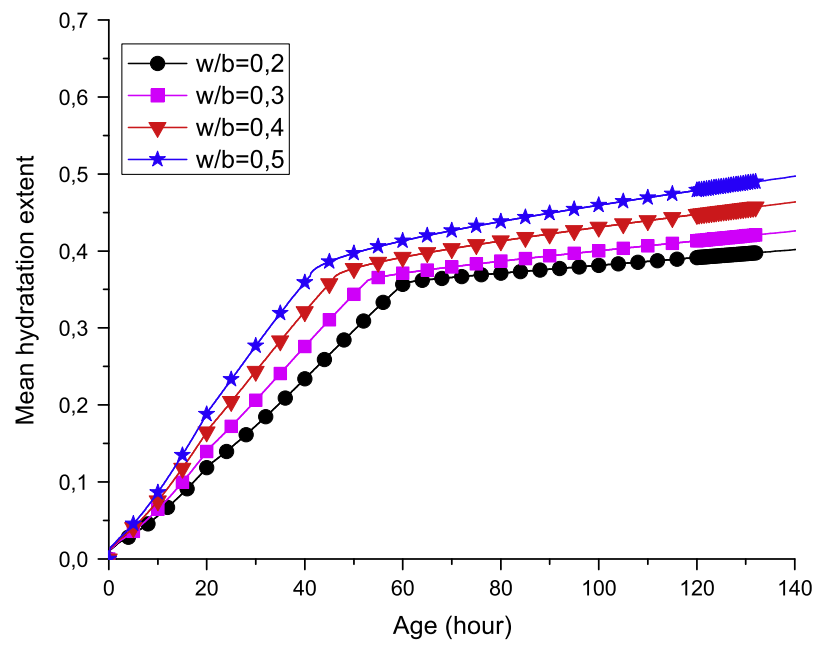

(a) $30 \%$ slag

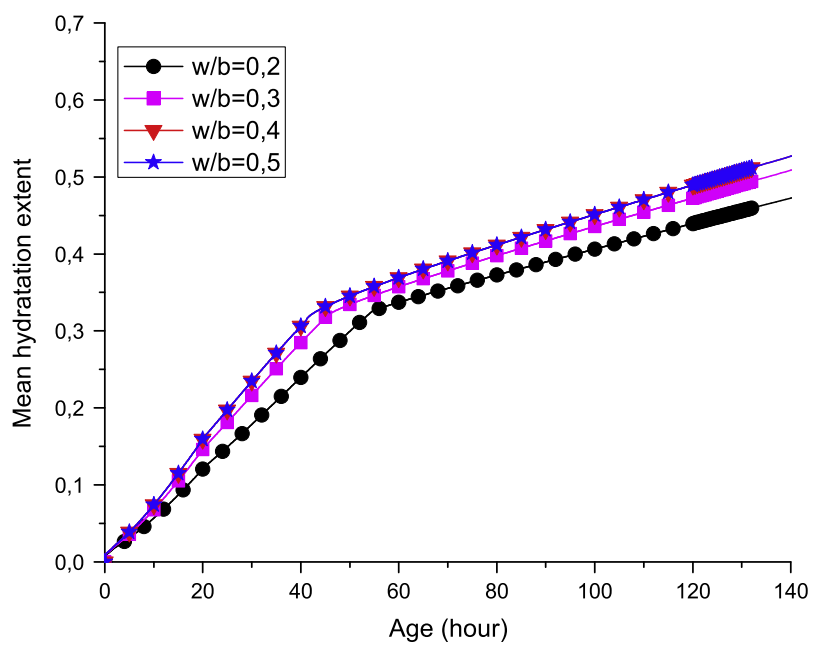

(b) $50 \%$ slag

Fig. 4. Sensitivity analysis of proposed model: effect of the $w / b$ ratio on the hydration degree of a slag-blended cement with $3460 \mathrm{~cm}^{2} / \mathrm{g}$ of fineness. parameters and the slag proportion in cement. The variation of the pre-exponential factor $k_{0}$ and the activation energy $E$ are given by the following expression as a function of the slag proportion $\lambda$ :

$\left\{\begin{array}{l}k_{0}=10.4605 \lambda-1.8289 \\ E(J)=13934.2105 \lambda+11264.4211\end{array}\right.$

Fig. 3 presents the measured remained Portlandite $(\mathrm{CH})$ (g/g binder) versus the curing time.

The experimental remained Portlandite is measured by Thermo-Gravimetric Analysis. In the hydration of cement-slag blends, the evolution of the $\mathrm{CH}$ mass depends on two mechanisms: the Portland cement hydration that produces $\mathrm{CH}$ and the reaction of slag that consumes $\mathrm{CH}$. For low slag content, a large amount of $\mathrm{CH}$ is produced by the hydration of the cement. In a case of low cement content, the amount of $\mathrm{CH}$ produced by the hydration of clinker is not sufficient for the hydration of slag. So, the slag hydration consumes all the $\mathrm{CH}$ produced.

\subsection{Sensitivity analysis}

This section, presents the sensitivity analysis of the developed model. This is performed by choosing a baseline condition, and then one of the independent parameters is varied. Two input parameters are considered for this analysis: the water to binder

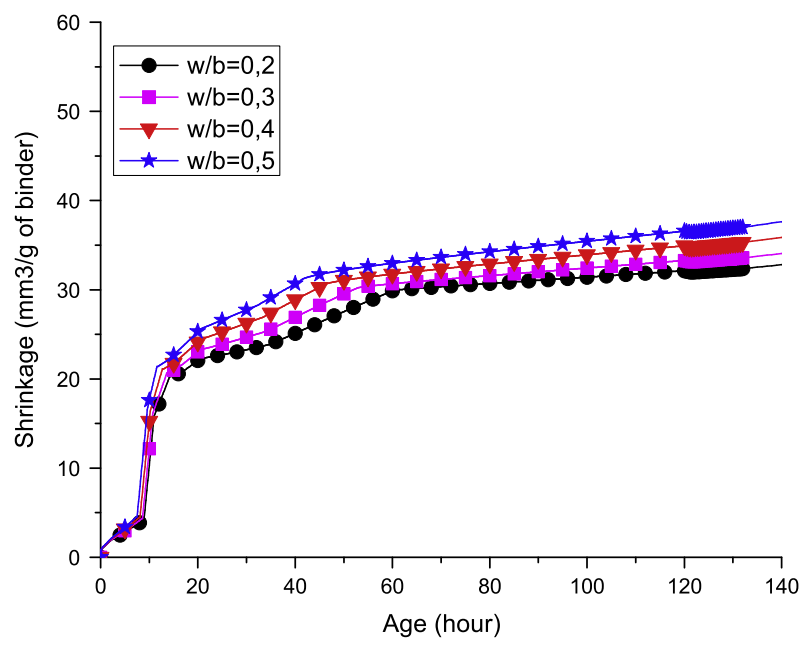

(a) $30 \%$ slag

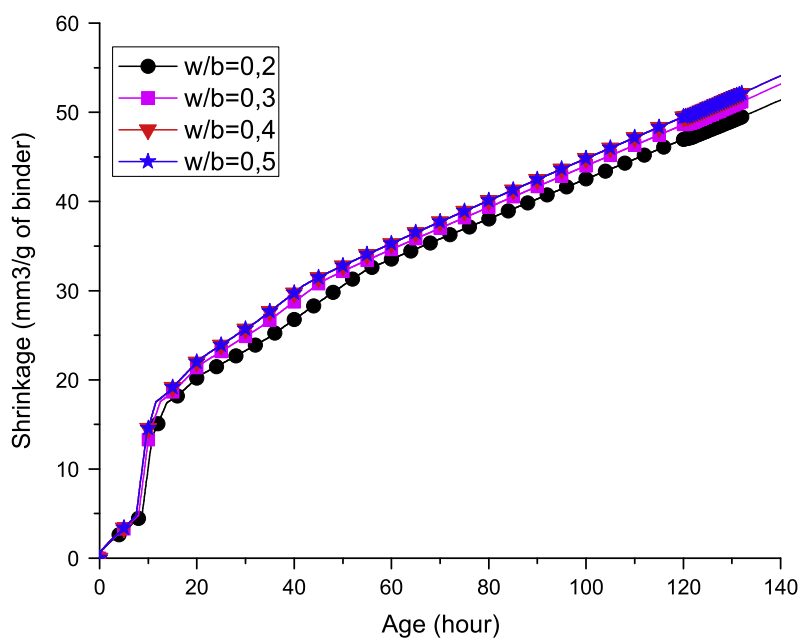

(b) $50 \% \mathrm{slag}$

Fig. 5. Sensitivity analysis of proposed model: effect of the $w / b$ ratio on the chemical shrinkage of a slag-blended cement with $3460 \mathrm{~cm}^{2} / \mathrm{g}$ of fineness. 
ratio, the fineness and the temperature. The results obtained from the sensitivity analysis, provide insight to the contribution of each of the parameters to the overall hydration process.

\subsubsection{Effect of the water to binder ratio}

Three different ratios: $0.2,0.3$ and 0.4 are used to study the effect of the $w / b$ ratio at $20^{\circ} \mathrm{C}$. The fineness of the slag-cement used is $3460 \mathrm{~cm}^{2} / \mathrm{g}$. Figs. 4 and 5 illustrate the effect of the water to binder ratio on the hydration degree and the chemical shrinkage of the slag cement pastes for a slag content of $30 \%$ and $50 \%$, respectively. According to this figure, increasing the $\mathrm{w} / \mathrm{b}$ ratio increases the degree of hydration at a given time " $t$ ". For a slag content of $50 \%$, the effect of the $\mathrm{w} / \mathrm{b}$ ratio on hydration is less important than the case with $30 \%$ slag. It is also noteworthy that for a slag content of $50 \%$ and for a $w / b$ ratio greater than or equal to 0.4 we observe that the degree of hydration does not change. This can be explained by the high amount of water present in the matrix with $50 \%$ slag content which generates the same level of hydration reactions regardless of a $w / b$ ratio greater than 0.4 . According to Fig. 5 , the effect of the $w / b$ ratio becomes significant on the chemical shrinkage results from $12 \mathrm{~h}$ hydration. Indeed, by this time, the water initially present in the pores is then consumed by the hydration

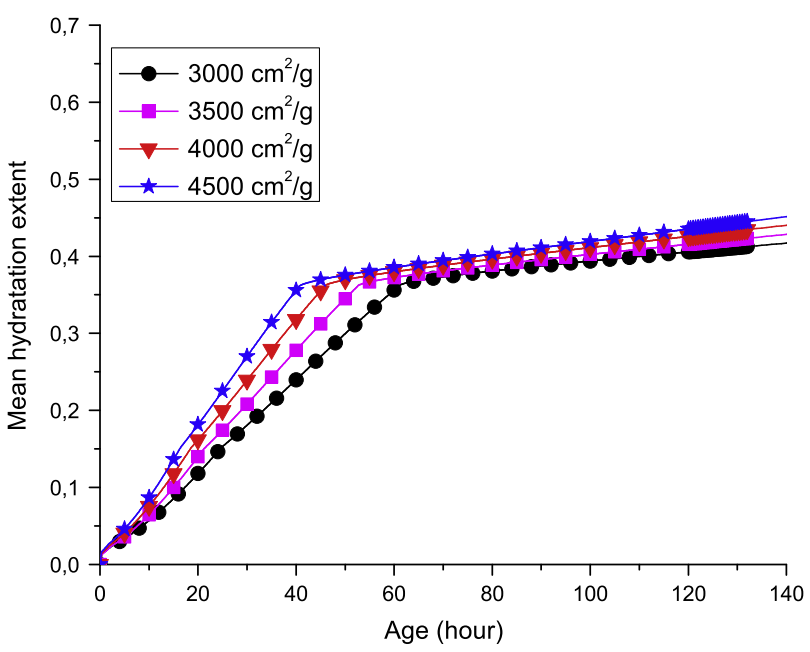

(a) $30 \%$ slag

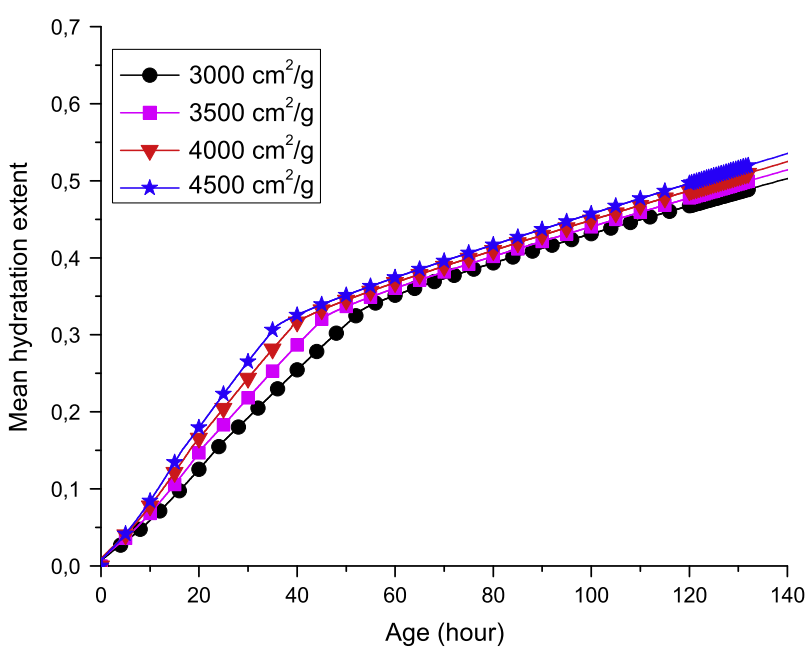

(b) $50 \%$ slag

Fig. 6. Sensitivity analysis of proposed model: effect of the cement fineness on the hydration degree of a slag-blended cement with $w / b=0.32$. reactions. This phenomenon is the cause of the appearance of voids in the pores, and that will be recorded as a chemical shrinkage.

\subsubsection{Effect of the cement fineness}

The effect of cement fineness was also investigated using four values: $3000,3500,4000$ and $4500 \mathrm{~cm}^{2} / \mathrm{g}$ with water to binder ratio of 0.32 and at a temperature of $20^{\circ} \mathrm{C}$. The cement fineness is defined by the cement particle size distribution. Previous experimental studies have shown that an increase in the cement fineness causes an acceleration of the cement hydration $[3,50,52,53]$. In the present model, calculations have been performed to quantify the influence of this parameter on the results provided by the model. The input cement composition is the same as defined below and the $\mathrm{w} / \mathrm{b}$ ratio is equal to 0.32 . The modeling results of the hydration degree and the chemical shrinkage are presented in Figs. 6 and 7, respectively, for various cement fineness. As expected, the highest cement fineness accelerates the hydration reactions (Fig. 6). This is due to the larger surface area of cement grains that are exposed to water and then more nucleation area. This is in accordance with past research findings [3,52]. It is also important to note that increasing the cement fineness accelerates the hydration reactions but it has a tendency to not change the fi-

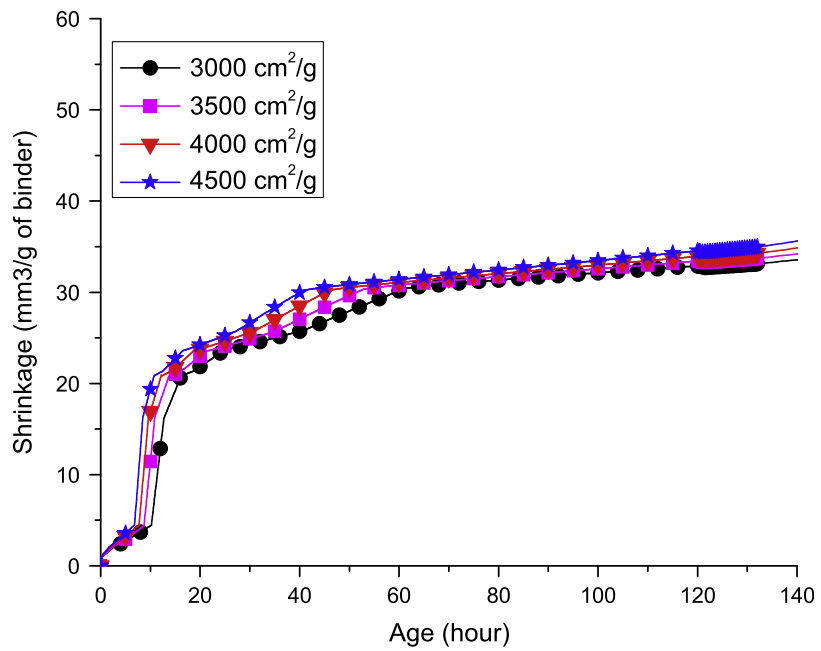

(a) $30 \%$ slag

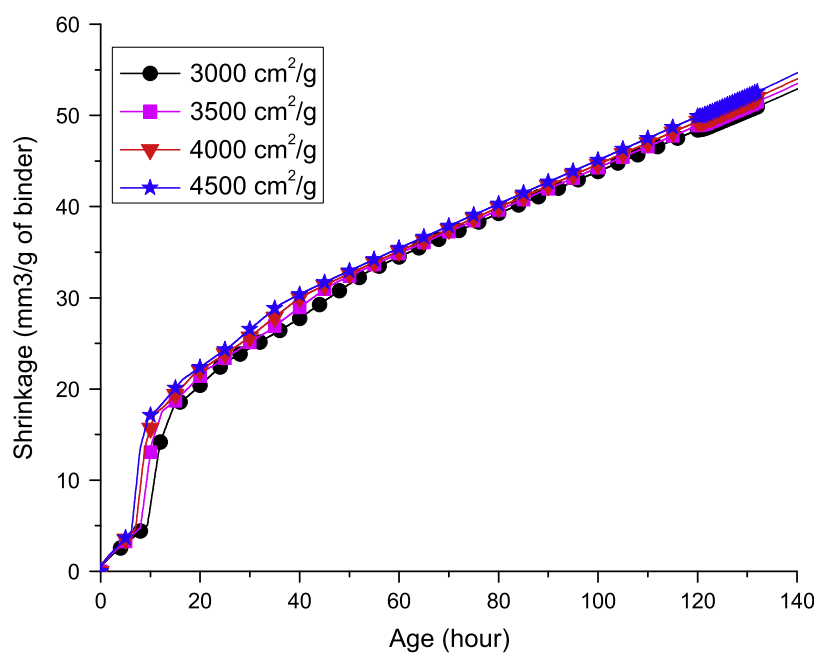

(b) $50 \%$ slag

Fig. 7. Sensitivity analysis of proposed model: effect of the cement fineness on the chemical shrinkage of a slag-blended cement with $w / b=0.32$. 
nal hydration degree. The results of chemical shrinkage (Fig. 7), which is a direct consequence of the hydration reactions show the same tendency but a smaller difference compared to the hydration ones.

\subsubsection{Effect of temperature}

The effect of temperature was investigated using four values: $20^{\circ} \mathrm{C}, 30^{\circ} \mathrm{C}, 40^{\circ} \mathrm{C}$ and $50^{\circ} \mathrm{C}$ with water to binder ratio of 0.32 and $3460 \mathrm{~cm}^{2} / \mathrm{g}$ of fineness. It shows that the temperature plays an important role on the hydration of the slag-blended cement.

Figs. 8 and 9 present the effect of the temperature on the hydration degree and the chemical shrinkage of the slag cement pastes for a slag content of $30 \%$ and $50 \%$, respectively. According to theses figures, increasing the temperature increases the degree of hydration at a given time " $t$ ". As expected, the highest temperature accelerates the hydration reactions but it has a tendency to not change the final hydration degree (Fig. 8). For a slag content of $50 \%$, the effect of the temperature becomes significant compared to the case of $30 \%$.

The results of chemical shrinkage (Fig. 7), which is a direct consequence of the hydration reactions show the same tendency but an important difference for a slag content of $50 \%$, and the effect

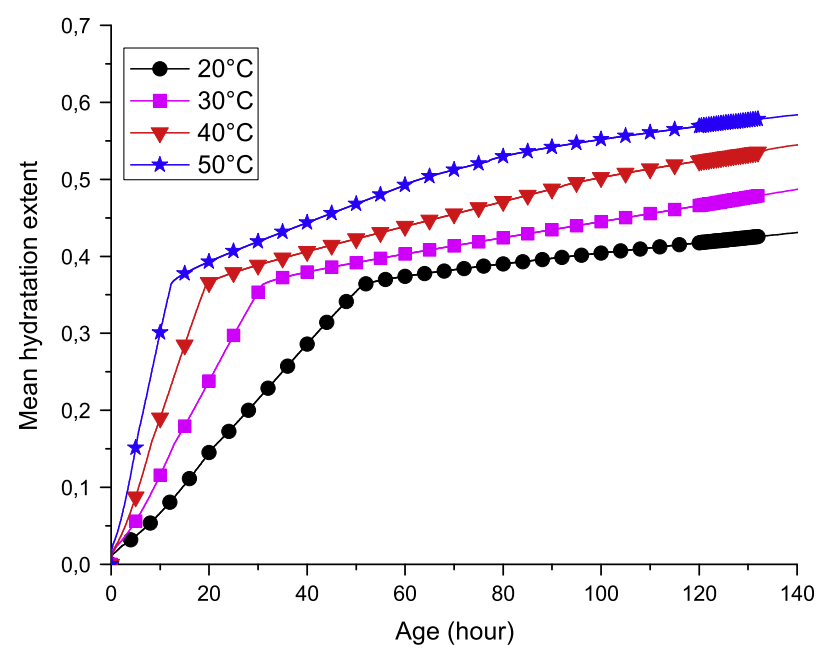

(a) $30 \%$ slag

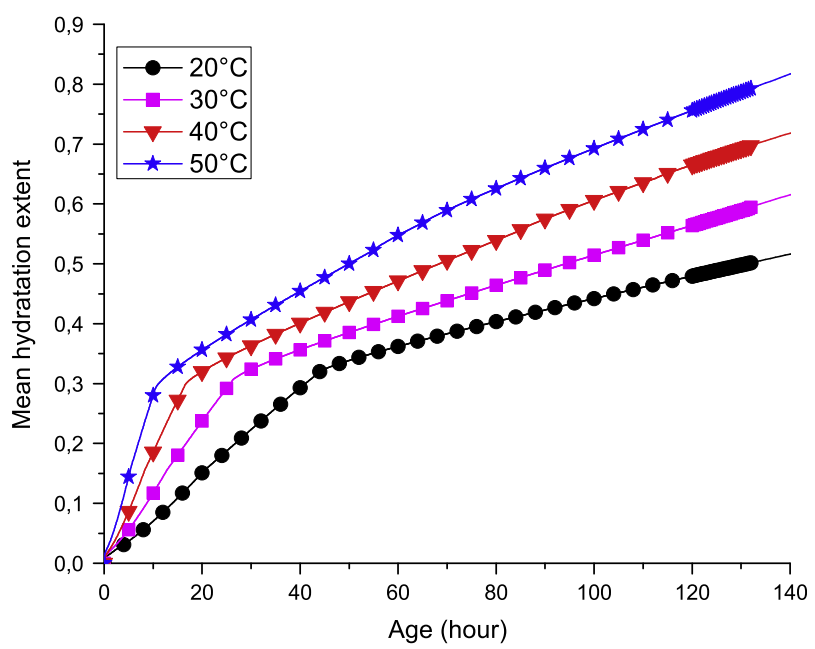

(b) $50 \%$ slag

Fig. 8. Sensitivity analysis of proposed model: effect of the temperature on the hydration degree of a slag-blended cement with $w / b=0.32$ and $3460 \mathrm{~cm}^{2} / \mathrm{g}$ of fineness. of the temperature becomes important when the hydration time increases.

\subsection{Comparison between computed and measurement results}

Fig. 10 presents the measured versus predicted hydration degree of slag-blended cement with different slag proportions using the identified parameters. The measured and predicted hydration degree versus time are also presented. The experimental hydration rate is calculated from the heat of hydration results: it is the ratio of the heat of hydration released at a "t" time on the total heat released for a complete reaction.

For low slag content $(0 \%, 30 \%)$, a significant difference is observed between computed and experimental results during the first curing hours. Beyond $50 \mathrm{~h}$, the predictions are in good agreement with the measurements. For high slag content (50\% and $80 \%$ ), the opposite effect is observed. In fact the model is able to predict only the first few hours of hydration ( $30 \mathrm{~h}$ and $15 \mathrm{~h}$ for slag content of $50 \%$ and $80 \%$, respectively). Beyond, that the model results diverge from the experimental ones. According to Fig. 10b and from $30 \mathrm{~h}$ of curing time, the effect of the slag is clearly iden-

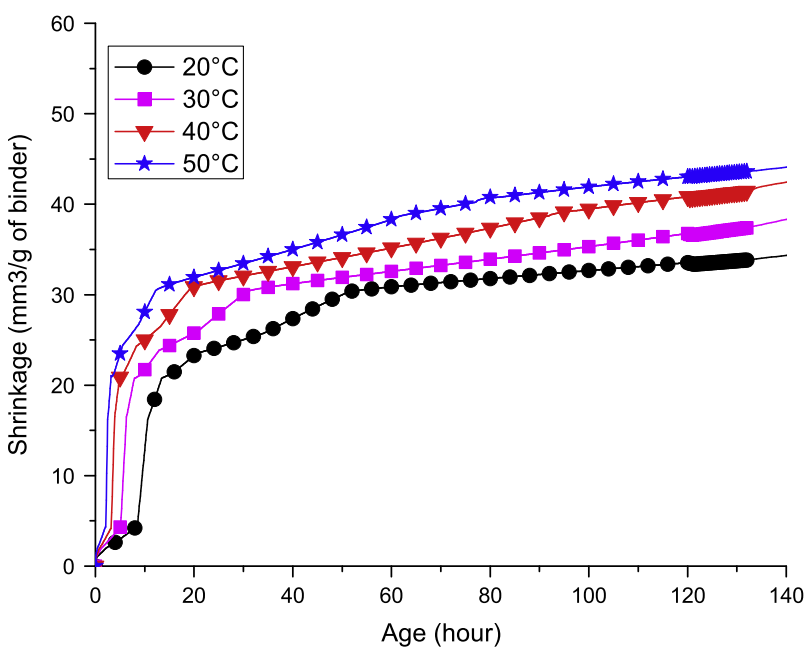

(a) $30 \%$ slag

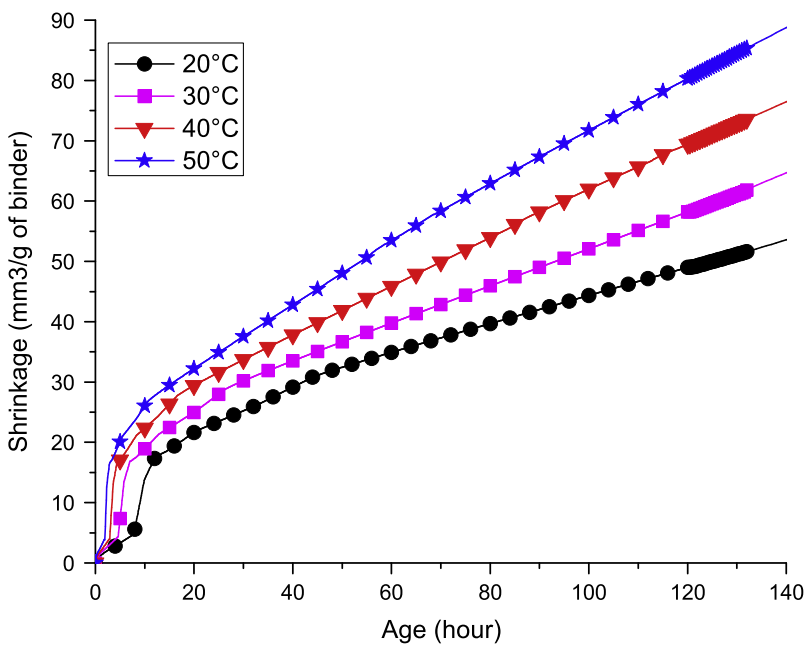

(b) $50 \%$ slag

Fig. 9. Sensitivity analysis of proposed model: effect of the temperature on the chemical shrinkage of a slag-blended cement with $w / b=0.32$ and $3460 \mathrm{~cm}^{2} / \mathrm{g}$ of fineness. 


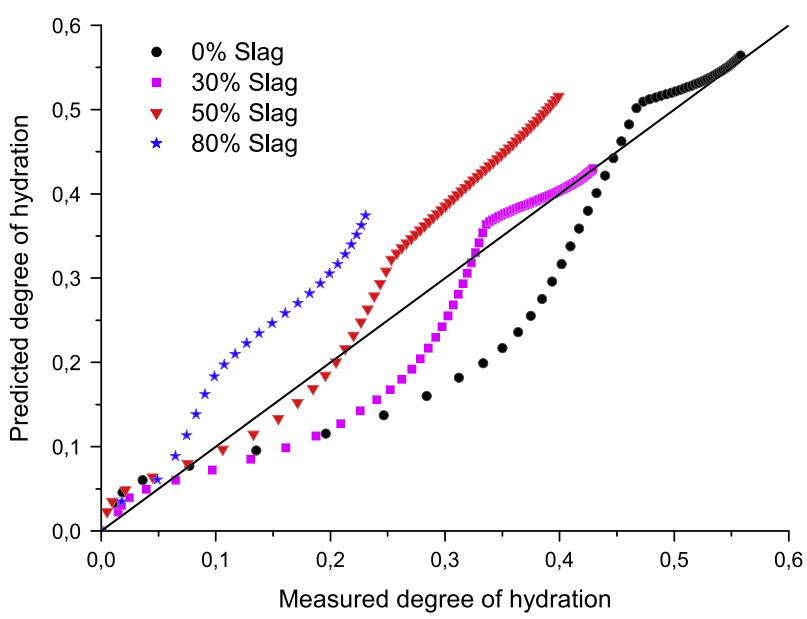

(a) Plot of measured versus predicted hydration degree

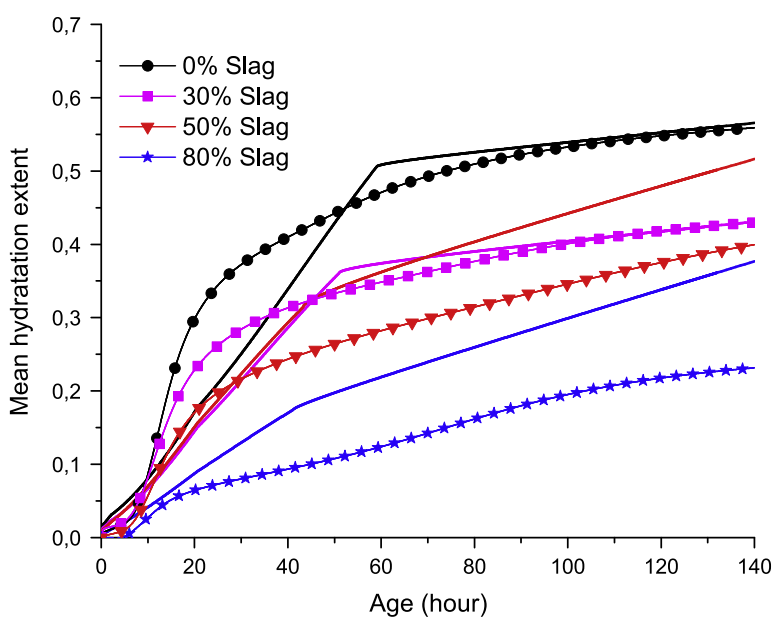

(b) Measured and predicted hydration degree versus time (continuous line : modeling results, dotted line : experimental ones)

Fig. 10. Hydration degree of binder with $w / b=0.32$.

tified. Indeed, increasing the slag content increases the slope of the curve of the hydration rate as a function of curing time. This effect is clearly observed in both numerical and experimental results. So, the model is able to predict the shape of the rate of reaction curve but the amplitude is different from the experimental data.

The comparison between the experimental and predicted chemical shrinkage results of the slag-blended cement is presented in Fig. 11. The measured and predicted results versus time are also given. A rather good agreement is obtained between the experimental and the numerical results with the exception of 30\% slag results. For the cement paste with $30 \%$ slag content, the experimental and the numerical curves diverge at $50 \mathrm{~h}$ of curing. The model underestimates the chemical shrinkage beyond $50 \mathrm{~h}$. At $140 \mathrm{~h}$, the gap between experimental and numerical values reached $20 \%$. The same is observed for the pure cement but with a smaller gap of $5 \%$ at $140 \mathrm{~h}$. As for hydration, the increase of the slag content accelerates the chemical shrinkage. At $150 \mathrm{~h}$, the slag-blended cement past with a slag content of $50 \%$, presents the highest chemical shrinkage.

Fig. 12 presents the measured versus numerical remained Portlandite $(\mathrm{CH})(\mathrm{g} / \mathrm{g}$ binder $)$ with $\mathrm{w} / \mathrm{b}=0.32$. The results over time are also given. According to Fig. 12 and for low slag content, a good agreement is observed between the predictions and the measured quantity of remained $\mathrm{CH}$. For high slag proportions, the measured

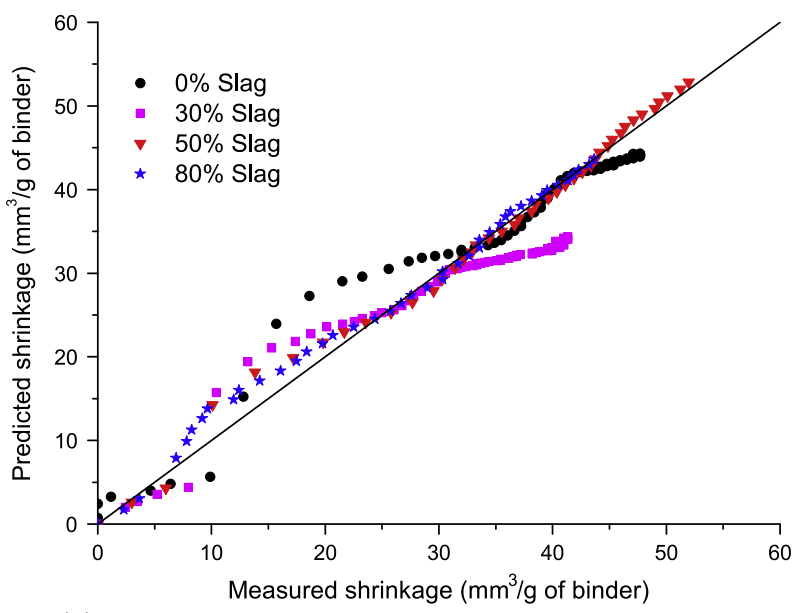

(a) Plot of measured versus predicted chemical shrinkage

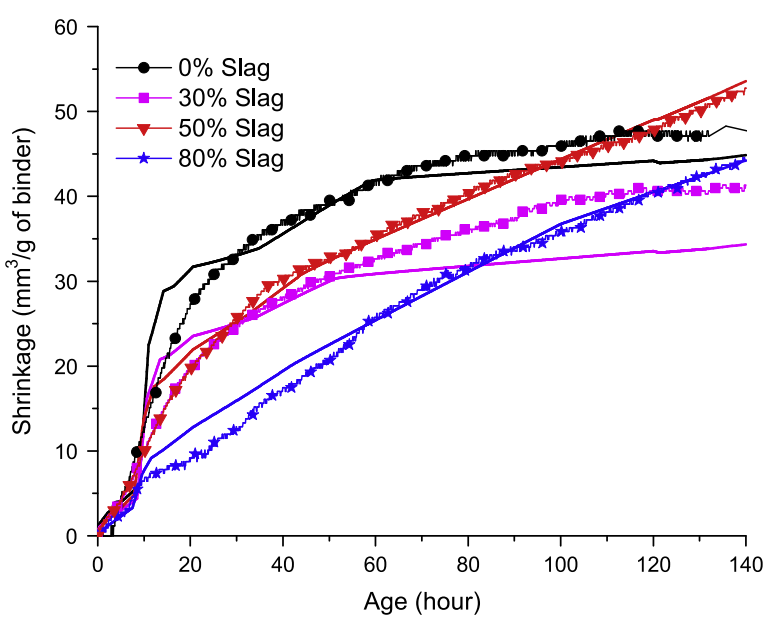

(b) Measured and predicted chemical shrinkage versus time (continuous line : modeling results, dotted line : experimental ones)

Fig. 11. Chemical shrinkage of binder with $w / b=0.32$

values of remained $\mathrm{CH}$ are different from the numerical ones. Indeed, the model tends to underestimate the $\mathrm{CH}$. The difference between the experimental and numerical results increases with increasing slag content. For low slag content, a large amount of $\mathrm{CH}$ is produced by the hydration of the cement. Consequently, the $\mathrm{CH}$ is sufficient to ensure the $\mathrm{C} / \mathrm{S}$ ratio of 1.42 in $\mathrm{C}-\mathrm{S}-\mathrm{H}$. It is thus partially consumed. In case of low cement content, the amount of $\mathrm{CH}$ produced by the hydration of clinker is not sufficient to supply the constant C/S ratio of 1.42 in $\mathrm{C}-\mathrm{S}-\mathrm{H}$. So, the slag hydration consumes all the $\mathrm{CH}$ produced, and the $\mathrm{C} / \mathrm{S}$ ratio in $\mathrm{C}-$ $\mathrm{S}-\mathrm{H}$ is lower than 1.42 . In conclusion, with a higher slag content, both the amount of $\mathrm{CH}$ and its ratio to the amount of Portland cement are lower. This implies that a part of formed $\mathrm{CH}$ is consumed and this consumption is increased by increasing slag content.

The difference between the experimental and the simulation results for high slag proportions are not satisfactory compared to the measured ones. This difference shows the complexity of slag cement reaction and its modeling. The difference may be due to several factors: the lack of knowledge about the chemistry of slag reaction, the extreme complexity interaction between slag and Portland cement and the reactivity of slag in cement [27]. The reactivity of slag is influenced by several factors, some being the inherent properties of the slag itself, and the other being environmental factors [27]. 


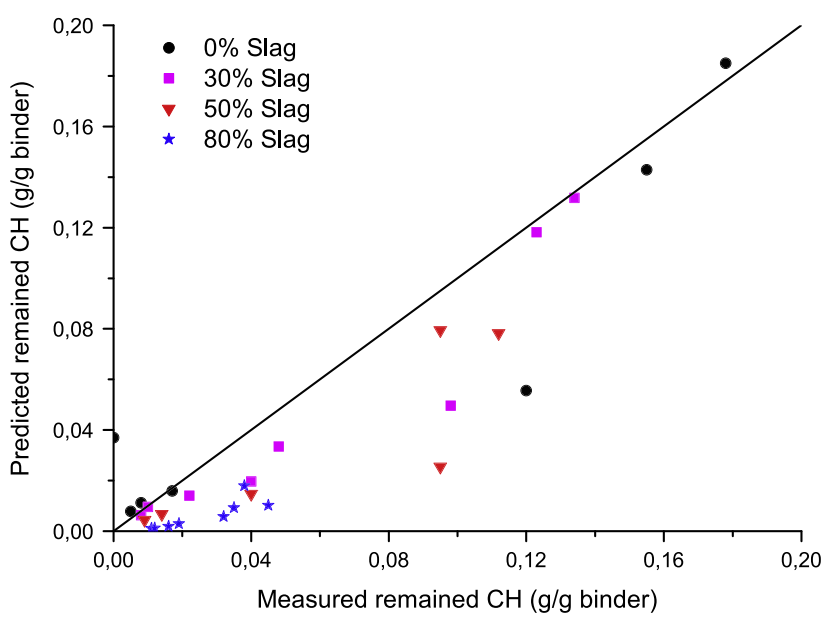

(a) Plot of measured versus predicted remained $\mathrm{CH}$

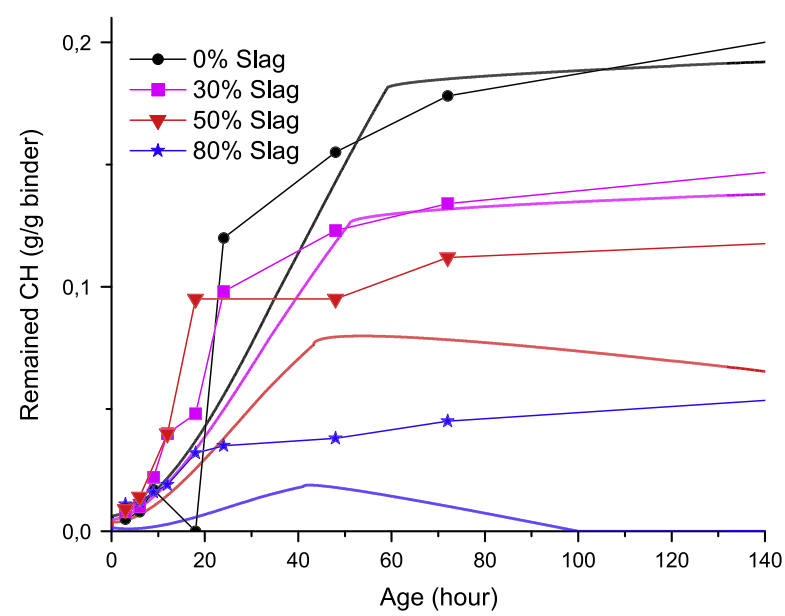

(b) Measured and predicted remained $\mathrm{CH}$ (g/g binder) versus time (continuous line : modeling results, dotted line : experimental ones)

Fig. 12. Remained $\mathrm{CH}(\mathrm{g} / \mathrm{g}$ binder) with $w / b=0.32$.

The difference may be also due to the interaction of the cement slag during hydration reactions [28,54]. The interlinked hydration model may be influenced by the concentration of pore solutions and $\mathrm{pH}$ level [28]. When $\mathrm{CH}$ does not become a critical factor in the hydration reactions, the mutual interactions can be considered through the amount of calcium hydroxide and capillary water left in the system [28]. It should be noted that, the shortage of $\mathrm{CH}$ induces a lackness of the slag hydration after which, slag particles may have a micro-filler effect on the other components of clinker. For a high slag proportion, this micro-filler effect becomes significant, and in the proposed model this effect is not taken into account. So, the difference between the experimental and the simulation results obtained by the proposed model at high slag proportion mainly comes from the ignorance of this micro-filler effect $[28,55]$.

Another difference may be the reduction in calcium ion concentration in the pore solution due to the presence of slag [56]. The differences could possibly be attributed to the slag's retardation and nucleation effects on cement hydration, that were not considered in the proposed model [49].

As mentioned in the above section, the highest level of fineness accelerates the hydration reaction. This is due to the larger surface area of grains that are exposed to water. However, this influence may become significant or the least significant for high slag proportion in slag-blended cement. This is not considered in the present work.

\section{Conclusion}

This work constitutes one more step to reinforce the studies concerning slag-blended cement hydration. In this paper, a kinetic model was proposed to describe the hydration process of Portland cement containing blast furnace slag (BFS). The reaction of slag was treated separately from that of cement hydration. The interactions between the cement hydration and slag reaction were considered through the available calcium hydroxide amount in the system. The Knudsen model was used to study the hydration of the slag using the stoichiometry of the reaction between slag and Portlandite $\mathrm{CH}$. The Knudsen parameters were identified from the experimental data. The model takes into account several parameters such as the chemical composition of cement and slag, the fineness, the curing temperature and the water to binder ratio $(w / b)$. Various slag contents are considered in the model. Calculation results were compared to experimental measurements. The result analysis of this study on the hydration and chemical shrinkage modeling of slag-blended cement are highlighted in the following points:

- The model correctly predicts the hydration rate of the slagblended cement pastes with low slag contents (0\% and 30\%). For higher slag content, the model underestimates the progress of hydration reactions but with a shape close to the one obtained experimentally.

- The model demonstrates that the presence of blast furnace slag causes an acceleration of the chemical shrinkage and the hydration process which were observed experimentally from the very first hours.

- Good agreements between experimental and simulation results were achieved for the chemical shrinkage.

- The measured values of retained $\mathrm{CH}$ are closed to the numerical values. This proves the model's ability to predict the amount of $\mathrm{CH}$ consumed by the slag reaction.

- A sensitivity study was proposed to show the influence of certain properties of the proposed model.

The model proves the ability to reproduce significant results of the hydration of slag-blended cement under several conditions. The model is of direct interest for studying hydration of cementitious materials containing blast furnace slag. Compared with experimental results, the obtained results are encouraging. It should be noted that, the identified parameters of this study depend only on this type of slag. To tend towards a refined predictive model, complementary studies would be required to identify all physical coupling between the two hydration processes of both Portland cement and blast furnace slag.

\section{References}

[1] Holt E, Leivo M. Cracking risks associated with early age shrinkage. Cem Concr Compos 2004;26(5):521-30.

[2] Lura P, Durand F. Volume changes of hardening concrete: testing and mitigation, ole mejlhede jensen, pietro lura and konstantin kovler. In: Proceeding of the international RILEM conference; 2006. pp. 57-65.

[3] Garcia Boivin S. Retrait au jeune ge du bton: Dveloppement dune mthode exprimentale et contribution lanalyse physique du retrait endogne. $\mathrm{PhD}$ thesis. Ecole Nationale des Ponts et Chausses; 1999.

[4] Bouasker M, Mounanga P. Turcry P. Loukili A, Khelidj A. Chemical shrinkage of cement pastes and mortars at very early age: effect of limestone filler and granular inclusions. Cem Concr Compos 2008;30(1):13-22.

[5] Mounanga Pierre, Khelidj Abdelhafid, Loukili Ahmed, Baroghel-Bouny Vronique. Predicting $\mathrm{Ca}(\mathrm{OH}) 2$ content and chemical shrinkage of hydrating cement pastes using analytical approach. Cem Concr Res 2004;34(2): 255-65. 
[6] Bernard Olivier, Ulm Franz-Josef, Lemarchand Eric. A multiscale micromechanics-hydration model for the early-age elastic properties of cement-based materials. Cem Concr Res 2003;33(6):1293-309.

[7] Pichler Christian, Lackner Roman, Mang Herbert A. A multiscale micromechanics model for the autogenous-shrinkage deformation of earlyage cement-based materials. Eng Fract Mech 2007;74:34-58.

[8] Regourd M. Cements made from blastfurnace slag. In: Leas chemistry of cement and concrete. 4th ed.; 1998.

[9] Escalante-Garcia JI, Sharp JH. Effect of temperature on the hydration of the main clinker phases in Portland cements: part ii, blended cements. Cem Concr Res 1998;28(9):1259-74.

[10] Neville AM. Properties of concrete. 4th ed.; 1995

[11] Wu X, Roy DM, Langton CA. Early stage hydration of slag-cement. Cem Concr Res 1983;13:277-86.

[12] Chen $W$, Brouwers $H$. The hydration of slag, part 2: reaction models for blended cement. J Mater Sci 2007;42:444-64.

[13] Moir GK, Lumley JS, Gollop RS, Taylor HFW. Degrees of reaction of the slag in some blends with Portland cements. Cem Concr Res 1996;26-1: 139-51.

[14] De Schutter G, Taerwe L. General hydration model for Portland cement and blast furnace slag cement. Cem Concr Res 1995;25(3):593-604.

[15] Schindler Anton K, Folliard Kevin J. Heat of hydration models for cementitious materials. ACI Mater J 2005;102-1:24-33.

[16] Richardson JM, Biernacki JJ, Stutzman PE, Bentz DP. Stoichiometry of slag hydration with calcium hydroxide. J Am Ceram Soc 2002;85-2:47-53.

[17] De Schutter G. Hydration and temperature development of concrete made with blast-furnace slag cement. Cem Concr Res 1999;29(1):143-9.

[18] De Schutter G. Fundamental study of early age concrete behaviour as a basis for durable concrete structures. Mater Struct 2002;35:15-21.

[19] Maekawa K, Chaube R, Kishi T. Modeling of concrete performance: hydration, microstructure formation and mass transport. London, New York: Routledge; 1998.

[20] Maekawa K, Ishida T. Modeling of structural performances under coupled environmental and weather actions. Mater Struct 2002;35:591-602.

[21] Tanaka Satoshi, Inoue Kazuhisa, Shioyama Yoshihide, Tomita Rokuro. Methods of estimating heat of hydration and temperature rise in blast furnace slag blended cement. ACI Mater J 1995;92:429-36.

[22] De Weerdt K, Ben Haha M, Le Saout G, Kjellsen KO, Justnes H, Lothenbach B. Hydration mechanisms of ternary Portland cements containing limestone powder and fly ash. Cem Concr Res 2011;41(3):279-91.

[23] Gruskovnjak A, Lothenbach B, Holzer L, Figi R, Winnefeld F. Hydration of alkaliactivated slag: comparison with ordinary Portland cement. Adv Cem Res 2006;18(3):119-28.

[24] Gruskovnjak A, Lothenbach B, Winnefeld F, Figi R, Ko S-C, Adler M, et al Hydration mechanisms of super sulphated slag cement. Cem Concr Res 2008;38(7):983-92.

[25] Pietersen HS, Bijen JMJM. Fly ash and slag reactivity in cements: Tem evidence and application of thermodynamic modelling. Stud Environ Sci 1994;60:949-60.

[26] Bentz DP. Cemhyd3d: a three-dimensional cement hydration and microstructure development modeling package. version 3.0. nistir 7232 . Report NISTIR 7232, NIST, Gaithersburg, MD.U.S; 2005.

[27] Wei Chen. Hydration of slag cement: theory, modeling and application. PhD thesis, University of Twente; 2006

[28] Wang Xiao-Yong, Lee Han-Seung. Modeling the hydration of concrete incorporating fly ash or slag. Cem Concr Res 2010;40(7):984-96.

[29] Richardson IG. The nature of C-S-H in hardened cements. Cem Concr Res 1999;29:1131-47.

[30] Taylor HFW. Cement chemistry. 2nd ed.; 1997.

[31] Biernacki JJ, Richardson JM, Stutzman PE, Bentz DP. Kinetics of slag hydration in the presence of calcium hydroxide. J Am Ceram Soc 2002;85(9).
[32] Knudsen T. The dispersion model for hydration of Portland cement: I, general concepts. Cem Concr Res 1984;14:62230.

[33] Jander W. Reactions in the solid state at high temperatures: I. Z Anorg Allgem Chem 1927;163(12):130.

34] Avrami M. Kinetics of phase change, i. J Chem Phys 1939;7:1103-12.

[35] Bouasker M. tude numrique et exprimentale du retrait endogne au trs jeune ge des pates de ciment avec et sans inclusions. PhD thesis, Universit de Nantes 2007.

[36] Grondin F, Bouasker M, Mounanga P, Khelidj A, Perronnet A. Physico-chemical deformations of solidifying cementitious systems: multiscale modelling. Mater Struct 2010;43:151-65.

[37] Odler I. Hydration, setting and hardening of Portland cement. In: Lea's chemistry of cement and concrete. Oxford: Butterworth-Heinemann; 2001. p. 241-89.

[38] Odler I. Hydration, setting and hardening of Portland cement. In: Hewlett P, editor. lea's chemistry of cement and concrete, vol. 85(2); 1987. p. 313-22.

[39] Taylor H. Cement chemistry. 2nd ed.; 1990.

40] Atkins PW. Physical chemistry. 5th ed.; 1994.

[41] Fuji K, Kondo W. Kinetics of the hydration of tricalcium silicate. J Am Ceram Soc 1974;57:492-502.

[42] Brouwers HJH. The work of powers and brownyard revisited: Part 1. Cem Concr Res 2004;34(9):1697-716.

[43] Harold H. Steinour, the system $\mathrm{CaO}-\mathrm{siO}_{2}-h_{2} \mathrm{O}$ and the hydration of the calcium silicates. Res. Lab. Of Portland Cement Association, by American Chemical Society. Reprinted from Chem Rev 40(3) (1947) 391-460.

[44] Brouwers $\mathrm{HJH}$. The work of powers and brownyard revisited: Part 2. Cem Concr Res 2005;35(10):1922-36.

[45] Berliner R, Popovici M, Herwig KW, Berliner M, Jennings HM, Thomas JJ. Quasielastic neutrons scattering study of the effect of water-to-cement ratio on the hydration kinetics of tricalcium silicate. Cem Concr Res 1998;262:231-43.

[46] H.J.H. Brouwers. The work of powers and brownyard revisited: Part 2. Cem Concr Res 2005;35(10):1922-36.

[47] Ballim Yunus, Graham Peter. The effects of supplementary cementing materials in modifying the heat of hydration of concrete. Mater Struc 2009;42:803-11.

[48] Mounanga Pierre, Khokhar Muhammad, Hachem Rana El, Loukili Ahmed. Improvement of the early-age reactivity of fly ash and blast furnace slag cementitious systems using limestone filler. Mater Struct 2011;44:437-53.

[49] Wang Xiao-Yong, Lee Han-Seung, Park Ki-Bong, Kim Jae-Jun, Golden Jay S. A multi-phase kinetic model to simulate hydration of slag-cement blends. Cem Concr Compos 2010;32(6):468-77.

[50] Tazawa Ei ichi, Miyazawa Shingo. Influence of cement and admixture on autogenous shrinkage of cement paste. Cem Concr Res 1995;25(2):281-7.

[51] Termkhajornkit Pipat, Nawa Toyoharu, Nakai Masashi, Saito Toshiki. Effect of fly ash on autogenous shrinkage. Cem Concr Res 2005;35(3):473-82.

52] Bentz Dale P, Garboczi Edward J, Haecker Claus J, Jensen Ole M. Effects of cement particle size distribution on performance properties of Portland cement-based materials. Cem Concr Res 1999;29(10):1663-71.

53] Binici Hanifi, Aksogan Orhan, Cagatay Ismail H, Tokyay Mustafa, Emsen Engin. The effect of particle size distribution on the properties of blended cements incorporating ggbfs and natural pozzolan (np). Powder Technol 2007;177(3):140-7.

[54] Koichi Maekawa, Rajesh Chaube, Toshiharu Kishi. Modeling of concreteperformance: hydration. Microstructure formation and mass transport; 1998

[55] Koichi Maekawa, Tetsuya Ishida, Toshiharu Kishi. Multi-scale modeling of structural concrete; 2009

[56] Wang Xiao-Yong, Cho Hyeong-Kyu, Lee Han-Seung. Prediction of temperature distribution in concrete incorporating fly ash or slag using a hydration model. Compos Part B: Eng 2011;42(1):27-40. 